\title{
Investor Inattention and Friday Earnings Announcements
}

\author{
STEFANO DELLAVIGNA and JOSHUA M. POLLET* \\ February 2, 2008 \\ Forthcoming, Journal of Finance
}

\begin{abstract}
Does limited attention among investors affect stock returns? We compare the response to earnings announcements on Friday, when investor inattention is more likely, to the response on other weekdays. If inattention influences stock prices, we should observe less immediate response and more drift for Friday announcements. Indeed, Friday announcements have a 15\% lower immediate response and a $70 \%$ higher delayed response. A portfolio investing in differential Friday drift earns substantial abnormal returns. In addition, trading volume is $8 \%$ lower around Friday announcements. These findings support explanations of post-earnings announcement drift based on underreaction to information caused by limited attention.
\end{abstract}

*DellaVigna is from the Department of Economics, University of California, Berkeley. Pollet is from the Department of Finance, University of Illinois at Urbana-Champaign. A previous version of the paper was distributed under the title "Strategic Release of Information on Friday: Evidence from Earnings Announcements". We thank John Campbell, David Card, Raj Chetty, James Choi, Kent Daniel, Yonca Ertimur, John Graham, David Hirshleifer, Wei Jiang, Lawrence Katz, David Laibson, Owen Lamont, Ulrike Malmendier, Maria Nondorf, Ashley Pollet, Allen Poteshman, Torsten Persson, Matthew Rabin, Jeremy Stein, Xiao-Jun Zhang, and audiences at Duke (Fuqua), the Hong Kong University of Science and Technology, IIES (Stockholm), London Business School, Northwestern (Kellogg), Stanford University (GSB), University College (London), UC Berkeley, UI Urbana-Champaign, University of Zürich, the Adam Smith Asset Pricing Conference (LBS), the AEA Meetings 2005, the SITE 2004 (Psychology and Economics), and the Yale Conference on Behavioral Science for valuable comments. Jessica Chan, Eric Fleekop, Richard Kim, Clarice Li, Ming Mai, Raymond Son, Matthew Stone, and Terry Yee helped collect the announcement dates from the newswires. Dan Acland, Saurabh Bhargava, and Tatyana Deryugina provided excellent research assistance. 
Investors have a limited amount of time and cognitive resources to process information. Despite the intuitive appeal of limited attention, little evidence exists on the extent to which the quality of decision-making by investors declines in response to distractions. Incentives, information aggregation across investors, and arbitrageurs may eliminate the effects of limited attention.

We examine a decision where attention to new information plays a crucial role, the response to earnings surprises. We compare announcements that occur just before the weekend, on Friday, to announcements on other weekdays. If weekends distract investors and lower the quality of decision-making, the immediate response to Friday earnings surprises should be less pronounced. As investors revisit their decisions in subsequent periods, the information should eventually be incorporated in stock prices. As a result, the delayed response, measured by the post-earnings announcement drift, should be of greater magnitude for Friday announcements. If limited attention, instead, does not affect stock prices, the response to announcements should not differ for Friday and non-Friday announcements.

This paper, therefore, addresses the debate on the explanation for the post-earnings announcement drift (Chan, Jegadeesh, and Lakonishok, 1996; Bernard and Thomas, 1989). Behavioral explanations depend on disposition effect (Grinblatt and Han, 2005; Frazzini, 2006), fluctuations in overconfidence (Daniel, Hirshleifer, and Subrahmanyam, 1998), beliefs about mean reversion (Barberis, Shleifer, and Vishny, 1998), or underreaction to information due to cognitive limits (Hong and Stein, 1999). Of the explanations in the literature, only underreaction to information makes the prediction that distractions increase the drift.

The paper proceeds as follows. In Section I we present a model of the response of stock prices to signals about earnings. In each period, a share of the agents is distracted and does not observe a signal regarding company performance. Given limits to arbitrage in the form of risk aversion, the distracted agents affect prices. A larger share of inattentive investors shrinks the immediate response and magnifies the delayed response of prices to the signals. Distraction, therefore, increases the post-earnings announcement drift. The combined response to the announcement, however, is not affected by the distracted investors. We also show that companies that maximize short-term share value release bad news on high-distraction days.

In Section II, we characterize our sample of earnings announcements from January 1995 until June 2006. Since we analyze the difference between Friday and non-Friday announcements, the accuracy of the announcement date is critical. We devise a rule, based on newswire announcement dates, that identifies the correct announcement date from $I / B / E / S$ and $C O M$ PUSTAT data with more than $95 \%$ accuracy. This rule can be used to improve the accuracy of the $I / B / E / S$ announcement date from 1984 onward.

In Section III, we evaluate the immediate and delayed stock return response to information by comparing the top and bottom quantile of the earnings surprise. The immediate stock re- 
sponse is $15 \%$ lower for Friday announcements than for non-Friday announcements. Conversely, the delayed response is $70 \%$ larger for Friday announcements. We combine these findings in a summary measure. The delayed response as a percentage of the total response is $60 \%$ on Friday and $40 \%$ on other weekdays. According to our model, these estimates imply that the share of distracted agents in the economy is at least $60 \%$ on Friday and $40 \%$ on other days.

While our initial analysis is focused on the top and bottom quantiles, we also examine the immediate and delayed response for the entire sample of earnings announcements. The results from this regression analysis are quantitatively similar and more precisely estimated. In addition, we construct portfolios to measure the differential post-earnings-announcement drift for Friday announcements. A trading strategy which purchases (long position) the Friday drift and sells (short position) the non-Friday drift earns abnormal returns of approximately 4 percentage points per month.

These findings are consistent with weekend distractions altering the investor response to earnings information. Individuals are more likely to underreact initially to Friday announcements. Eventually, investors become aware of the information they neglected and trade accordingly. The stronger delayed response (larger drift) reverses the initial underreaction.

If investors are more distracted on Friday, we also expect lower abnormal trading volume for Friday announcements. In Section IV, we find that the abnormal volume is indeed $8 \%$ lower for Friday announcements than for non-Friday announcements.

The stock return and volume results suggest that investors exhibit a lower immediate response to Friday announcements. Managers that maximize short-term value should respond by releasing worse announcements on Friday. The results in this paper, therefore, provide an explanation for the known findings of worse earnings (and dividend) announcements on Friday (Penman, 1987; Damodaran, 1989; Bagnoli, Clement, and Watts, 2005).

In Section V we consider alternative interpretations of the findings. First, the slower response to Friday announcements may be due to mechanical differences between Friday and non-Friday announcements due to the extended trading stoppage or to a larger share of announcements made after the market is closed. However, the two-day break after Friday announcements should allow investors more time to respond and thereby reduce the underreaction. Moreover, during the sample period Friday announcements are less likely to be released after the market closes. Second, the slower response to Friday announcements may be caused by pre-announcement leakage of information. However, the stock returns during the 30 days before the announcement do not differ systematically for Friday and non-Friday announcements after conditioning on earnings news. Third, the slower response to Friday announcements could be due to systematic differences in the characteristics of companies announcing on Friday. While it is impossible to fully control for company heterogeneity, the results are robust 
to the introduction of time, market capitalization, and earnings surprise volatility controls.

The results in this paper are related to the literature on inattention in finance (Barber and Odean, forthcoming; Cohen and Frazzini, forthcoming; DellaVigna and Pollet, 2007; Dyck and Zingales, 2003; Hirshleifer and Teoh, 2003; Hong and Stein, 1999; Huberman and Regev, 2001; Peng and Xiong, 2006) and economics (Gabaix et al., 2006). From this standpoint, our key finding is that a proxy for inattention increases the delayed reaction of stock prices to new information. This result supports the theory that momentum effects (Jegadeesh and Titman 1993) and post-earnings announcement drift (Chan, Jegadeesh, and Lakonishok, 1996; Bernard and Thomas, 1989) are caused by underreaction to new information due to cognitive constraints. In a related paper, Hirshleifer, Lim, and Teoh (2007) show that the response of stock prices to earnings news is delayed on days with more earnings announcements, a proxy of distraction. The evidence in our paper about the speed of information assimilation by weekday differs from the previous evidence on aggregate return and trading volume by weekday (French, 1980; Keim and Stambaugh, 1984).

Finally, this paper is an additional example of a market response to a bias, in this case investor inattention. This is a long-standing theme in finance (Baker, Ruback, and Wurgler, forthcoming; DeLong et al., 1990; Shleifer, 2000) and it has more recently been applied to firm pricing (DellaVigna and Malmendier, 2004; Gabaix and Laibson, 2006).

\section{Model}

We present a model of portfolio choice where all investors are exposed to a signal about next period's dividend, but the fraction of investors that pay attention to this signal varies (e.g., by weekday). While managers cannot manipulate the signal itself as in Hirshleifer and Teoh (2003), they choose to announce the signal when either a high fraction or a low fraction of investors is distracted.

Setup. The risky asset has price $P_{t}$, pays a risky dividend $D_{t+1}$ before the start of period $t+1$, and is in fixed supply. The dividend $D_{t+1}$ is equal to $\delta+s_{t}+\varepsilon_{t+1}$ where $s_{t} \sim N\left(0, \sigma_{s}^{2}\right)$ is the signal broadcast to the public before the start of period $t$ and $\varepsilon_{t+1} \sim N\left(0, \sigma_{\varepsilon}^{2}\right)$ is the random component that is unknown until the end of period $t$. We assume that $s_{t}$ and $\varepsilon_{t}$ are contemporaneously independent and are drawn identically and independently across periods. The riskless asset has a price normalized to 1 , a gross return of $1+R$ every period, and is in perfectly elastic supply.

There is a continuum of investors on the interval $[0,1]$ where a fraction $1-\mu_{t}$ of investors observes the signal $s_{t}$ (the attentive investors) and a fraction $\mu_{t}$ of investors does not (the distracted investors). The manager observes the signal $s_{t}$ and then decides to release the signal on a high-distraction day denoted $\mu_{t}=\mu_{h}$ (e.g., Friday) or on a low-distraction day denoted 
$\mu_{t}=\mu_{l}$ (e.g., another weekday), where $0 \leq \mu_{l} \leq \mu_{h} \leq 1$. The model analyzes an overlapping generations framework where all wealth is consumed at the end of each period (quarter).

Portfolio choice. At the beginning of quarter $t$, agent $i$ invests $\lambda_{t}^{i}$ units in the risky asset in order to maximize end-of-period wealth $W_{t}^{i}$. Attentive investors use the signal $s_{t}$ to make this decision, while distracted investors do not. We define $E_{t}^{i}[$.$] and \sigma_{i, t,(.)}^{2}$ as the conditional expectation and variance operators respectively, using the information set for individual $i$. For example, the expected dividend for attentive investors (where $i>\mu_{t}$ ) is denoted $E_{t}^{i}\left[D_{t+1}\right]=$ $E_{t}^{1-\mu}\left[D_{t+1}\right]=\delta+s_{t}$ and the expected dividend for distracted investors (where $i \leq \mu_{t}$ ) is denoted $E_{t}^{i}\left[D_{t+1}\right]=E_{t}^{\mu}\left[D_{t+1}\right]=\delta$. Each investor has a quadratic utility function with risk aversion parameter $\gamma>0$. The $i^{\text {th }}$ individual solves

$$
\begin{gathered}
\max _{\lambda_{t}^{i}} E_{t}^{i}\left[W_{t+1}^{i}\right]-\frac{\gamma}{2} \operatorname{Var}_{t}^{i}\left[W_{t+1}^{i}\right] \\
\text { s.t. } W_{t+1}^{i}=\lambda_{t}^{i}\left(P_{t+1}+D_{t+1}-P_{t}\right)+\left(W_{t}^{i}-\lambda_{t}^{i} P_{t}\right) R+W_{t}^{i} .
\end{gathered}
$$

Hence, the demand for the risky asset is

$$
\lambda_{t}^{i}=\frac{E_{t}^{i}\left[P_{t+1}+D_{t+1}\right]-P_{t}(1+R)}{\gamma \sigma_{i, t, P+D}^{2}} .
$$

Equilibrium. We impose the market clearing and transversality conditions to solve for the equilibrium price.

$$
P_{t}=\frac{\delta-\bar{a}}{R(1+R)}+\frac{\delta-a_{t}}{1+R}+\frac{1-b_{t}}{1+R} s_{t}
$$

where $a_{t}=\left[\mu_{t} /\left(\gamma \sigma_{\mu, t, P+D}^{2}\right)+\left(1-\mu_{t}\right) /\left(\gamma \sigma_{1-\mu, t, P+D}^{2}\right)\right]^{-1}, b_{t}=\mu_{t} /\left(\gamma \sigma_{\mu, t, P+D}^{2}\right) a_{t}, \bar{a}=\eta a\left(\mu_{h}\right)+$ $(1-\eta) a\left(\mu_{l}\right)$, and $\eta=\operatorname{prob}\left(\mu_{t+s}=\mu_{h}\right)$. Since $b_{t}$ increases with the fraction of distracted agents, inattention makes prices less responsive to signals.

Response to signal. We derive measures of the immediate and the delayed response of the stock price to the signal (e.g., an earnings announcement). Define the dollar excess return from $t-1$ to $t$ as $Z_{t}=P_{t}+D_{t}-(1+R) P_{t-1}$. The abnormal return from $t-1$ to $t$ is the change in expected returns due to new information. This abnormal return incorporates two sources of new information: the signal $s_{t}$ and the unexpected dividend $D_{t}-E_{t-1}\left[D_{t}\right]$. Since the second component is unrelated to the signal, we define the immediate response to the signal as $E_{t}\left[I R_{t}\right] \equiv Z_{t}-E_{t-1}\left[Z_{t}\right]-\left(D_{t}-E_{t-1}\left[D_{t}\right]\right)$.

The excess return for the second period $(t$ to $t+1)$ is $Z_{t+1}$. The change in the expectation for this excess return caused by the signal is $E_{t}\left[D R_{t+1}\right] \equiv E_{t}\left[Z_{t+1}\right]-E_{t-1}\left[Z_{t+1}\right]$. This measure captures the delayed response and is the theoretical equivalent of the post-earnings announcement drift. We also define the long-term response to the announcement $E_{t}\left[L R_{t+1}\right]$ 
as the discounted sum of $E_{t}\left[I R_{t}\right]$ and $E_{t}\left[D R_{t+1}\right]$. Once $D_{t+1}$ is paid to investors, the information in the signal $s_{t}$ is irrelevant for all subsequent investment decisions because expectations of future cashflows do not depend on $s_{t}$. Hence, the impact of distraction at $t$ on abnormal returns is fully resolved by $t+1 .^{1}$

Proposition 1.(i) The immediate response $E_{t}\left[I R_{t}\right]$ is a linear function of the signal $s_{t}$, with slope coefficient $\left(1-b_{t}\right) /(1+R)$. The slope $\left(1-b_{t}\right) /(1+R)$ is decreasing in the share of distracted investors $\mu_{t}$ and is equal to $1 /(1+R)$ if $\mu_{t}=0$.(ii) The delayed response $E_{t}\left[D R_{t+1}\right]$ is a linear function of the signal $s_{t}$, with slope coefficient $b_{t}$. The slope $b_{t}$ is increasing in the share of distracted investors $\mu_{t}$ and is equal to zero if $\mu_{t}=0$. (iii) The long-term response $E_{t}\left[L R_{t+1}\right]$ is a linear function of the signal $s_{t}$, with slope coefficient $1 /(1+R)$. The slope $1 /(1+R)$ is independent of the share of distracted investors $\mu_{t}$.

Inattentive agents delay the incorporation of information into the stock price. A larger fraction of these distracted agents lowers the immediate response and increases the delayed response to information. The immediate response on a high-distraction day is approximately proportional to the immediate response on a low-distraction day for identical signals, with the proportionality factor $\left(1-b_{h}\right) /\left(1-b_{l}\right)$. The long-term response does not depend on the share of inattentive investors.

We consider a summary measure for the delayed incorporation of news into stock prices. Let $s_{A}$ and $s_{B}$ be signals of different quality where $s_{A}>s_{B}$. We define the delayed response ratio as the ratio of the differential delayed response to the differential long-term response: $D R R_{t}=\left(E\left[D R_{t} \mid s_{A}, \mu_{t}\right]-E\left[D R_{t} \mid s_{B}, \mu_{t}\right]\right) /\left(E\left[L R_{t} \mid s_{A}, \mu_{t}\right]-E\left[L R_{t} \mid s_{B}, \mu_{t}\right]\right)$.

Corollary 1. (i) The delayed response ratio $D R R_{t}$ equals $b_{t}(1+R)$. (ii) $D R R_{t}$ is increasing in the share of distracted investors $\mu_{t}$ and is equal to zero if $\mu_{t}=0$. (iii) $D R R_{t}$ provides a bound on the share of distracted investors: $\mu_{t} \geq D R R_{t}$.

On high-distraction days a greater fraction of the long-term response is delayed. If there are no distracted investors, the delayed response ratio is zero. We use the bound $\mu_{t} \geq$ $(1+R) D R R_{t}$ in Section III.

Manager optimization. The manager of the firm can announce the signal on a highdistraction $\left(\mu_{t}=\mu_{h}\right)$ or a low-distraction day $\left(\mu_{t}=\mu_{l}\right)$. Long-term managers maximize the expected long-term price $E_{t}\left[P_{t+1}\right]$ and short-term managers maximize the current price $E_{t}\left[P_{t}\right]=P_{t}$.

Proposition 2. (i) Managers that maximize long-term value are indifferent between $\mu_{l}$ and $\mu_{h}$. (ii) Managers that maximize short-term value choose $\mu_{t}=\mu_{h}$ whenever $s_{t} \leq-\sigma_{s}^{2} \gamma$. It follows that $E\left[s_{t} \mid \mu_{t}=\mu_{h}\right]<E\left[s_{t} \mid \mu_{t}=\mu_{l}\right]$ and $E\left[I R_{t} \mid \mu_{t}=\mu_{h}\right]<E\left[I R_{t} \mid \mu_{t}=\mu_{l}\right]$.

Since the long-term price is independent of the fraction of distracted investors, long-term 
managers are indifferent about the release decision. Short-term managers with sufficiently negative news release the signal on high-distraction days because they prefer an attenuated immediate response. The threshold rule used by short-term managers implies that the average signal and immediate response are worse on high-distraction days. Hence, investor inattention explains the well-documented finding that earnings surprises and returns surrounding earnings announcements are lower for Friday announcements. (Penman, 1987; Damodaran, 1989; Bagnoli, Clement, and Watts, 2005).

\section{Data and summary statistics}

\section{A. Data}

Our sources of earnings data are $I / B / E / S$ and COMPUSTAT. We use the quarterly earnings announcements from $I / B / E / S$ for which at least one analyst forms an earnings forecast in the 90 days before the announcement. We restrict the sample to announcements that have stock return data in $C R S P$ and are reported in both $I / B / E / S$ and COMPUSTAT with a difference of at most 5 calendar days between the reported announcement dates. The resulting sample includes 228,651 announcements from January 1984 to June 2006.

We construct a measure of the announcement date using the reported COMPUSTAT and $I / B / E / S$ dates. In order to quantify the accuracy of these dates, we randomly select 2,487 earnings announcements for the period 1984 to 2002 and use Lexis-Nexis to search the announcement date in the PR newswires. We look for the function of the COMPUSTAT and $I / B / E / S$ dates that matches the newswire date most accurately. We oversample announcements that occur on Friday according to $I / B / E / S$. The results of the search (available upon request) suggest that the optimal imputation rule for the date differs for three categories of announcements:

1. $I / B / E / S$ and COMPUSTAT announcement dates differ. In the case of disagreement, the earlier date is usually the actual date of the announcement, and the later date is the date of publication in the Wall Street Journal. We impute the date to be the earlier one.

2. Before January 1, 1990: $I / B / E / S$ and COMPUSTAT announcement dates agree. In this case, most announcements are recorded using the Wall Street Journal date in both data sets. We assign the announcement date to be the previous trading date.

3. After January 1, 1990: $I / B / E / S$ and COMPUSTAT announcement dates agree. During this time period, the announcement date is usually from a newswire source. We impute the date to be the $I / B / E / S$ and COMPUSTAT date. 
After applying these rules, we measure the accuracy of the imputed announcement date (Table AI in the Appendix) for Friday and non-Friday announcements. Before 1995, a high number of earnings announcements were recorded with an error of at least one trading day. In addition, the errors are more common for Friday announcements than for non-Friday announcements. During the more recent years, the accuracy of the earnings date has increased substantially, and is almost perfect after December 1994. For the purposes of this paper, even a one-day error in the date is important, since it would lead to a misclassification of Friday announcements. In light of this evidence, we limit the analysis to the 154,051 earnings announcements taking place after 1994. In this period, the imputed earnings announcement date is correct more than $95 \%$ of the time for both Friday and non-Friday announcements.

As a measure of investor expectation, we use the consensus analyst forecast from $I / B / E / S$. The consensus forecast is defined as the median forecast among all the analysts that make a forecast in the last 30 calendar days before the earning announcement. If an analyst has made multiple forecasts in this time horizon, we use only the most recent one. ${ }^{2}$

We define the earnings surprise as the difference between the earnings announcement and the consensus earnings forecast, normalized by the price of a share (Kothari, 2001). Let $e_{t, k}$ be the earnings per share announced in quarter $t$ for company $k$ and $\hat{e}_{t, k}$ be the corresponding consensus analyst forecast ${ }^{3}$. Further, indicate by $P_{t, k}$ the price of the shares of company $k$ five trading days before the announcement in quarter $t$. The earnings surprise $s_{t, k}$ is

$$
s_{t, k}=\frac{e_{t, k}-\hat{e}_{t, k}}{P_{t, k}}
$$

We match the announcement dates with information on stock returns and trading volume from $C R S P$. We construct cumulative abnormal returns for different windows around the announcement date. Define $R_{\tau, k}$ the stock return of company $k$ on day $\tau$ and $R_{\tau, m}$ the market stock return on day $\tau$. We obtain $\hat{\beta}$ for company $k$ in quarter $t$ from the regression $R_{u, k}=\alpha_{t, k}+\beta_{t, k} R_{u, m}$ for days $u$ from $\tau-300$ to $\tau-46$, where $\tau$ is the date of the announcement in quarter $t$. The buy-and-hold abnormal return $R_{t, k}^{(h, H)}$ over time period $(\tau+h, \tau+H)$ for stock $k$ in quarter $t$ is then computed as $\left[\Pi_{j=\tau+h}^{\tau+H}\left(1+R_{j, k}\right)\right]-1-\hat{\beta}_{t, k}\left[\Pi_{j=\tau+h}^{\tau+H}\left(1+R_{j, m}\right)-1\right] .{ }^{4}$

We drop observations with a missing earnings surprise (8,853 observations), or in which the earnings announcement $e_{t, k}$ or the earnings forecast $\hat{e}_{t, k}$ are larger in absolute value than the price of a share $P_{t, k}$ (215 observations). We also eliminate penny stocks (812 observations) as well as announcements on Saturday, Sunday, or holidays (306 observations). Finally, we exclude observations with returns in the top and bottom 5/10,000th of the distributions for $R_{t, k}^{(0,1)}$ or $R_{t, k}^{(2,75)}$ (282 observations). The final sample includes 143,583 observations. 


\section{B. Summary statistics}

More than $80 \%$ of announcements occur on Tuesday, Wednesday, or Thursday, $13.8 \%$ occur on Monday and only $5.7 \%$ are on Friday (Table IA). The model can explain the small share of announcements on Friday - firms that commit to an announcement schedule never commit to announcements on a high-inattention day (Friday).

\section{Approximate location for Table I}

In Table IB we present summary statistics for the 8,166 Friday announcements (Column 1), and for the 135,417 non-Friday announcements (Column 2). Firms announcing on Friday have more negative earnings surprises and $10 \%$ smaller market capitalization. Friday announcements are more prevalent toward the beginning of the sample period. For non-Friday announcements, $60.59 \%$ of announcements occur in the first month of the quarter (January, April, July, and October), $31.14 \%$ in the second month, and only $8.27 \%$ in the third month. Friday announcements are more likely to occur in the second or third month.

Columns 4 and 5 present the summary statistics for companies with $10 \%$ to $90 \%$ of their announcements on Friday. This criterion excludes companies that rarely announce on Friday (116,251 observations) or that almost always announce on Friday (202 observations). In the remaining sample of 27,130 announcements, the summary statistics for announcements on Friday (Column 4) and other weekdays (Column 5) are closer. The controls for month of announcement are no longer significantly different, and the difference in the average year of announcement is reduced to less than two months. This subsample, labelled Homogeneous Sample, addresses to some extent the concern that companies announcing on Friday may have unobservable features that differ from companies announcing on other days.

\section{Stock return response}

In this Section, we examine the responsiveness of stock returns to earnings surprises at various horizons. We compare the responsiveness for announcements on Friday to the responsiveness for announcements on other weekdays. If the fraction of distracted investors is higher on Friday, there should be less immediate response to Friday announcements, followed by more delayed response; the total long-term response should be unchanged (Proposition 1). The fraction of the stock reaction occurring with delay should be higher for Friday announcements (Corollary 1). We present graphical evidence, followed by an analysis of earnings announcements in the top and bottom earnings quantiles including delayed response ratios, and by regressions using all announcements. Finally, we analyze the portfolio returns for a strategy that exploits the difference in drift between announcements on Friday and other weekdays. 


\section{A. Graphical evidence}

To measure announcement quality, we divide announcements into 11 bins, ordered by the earnings surprise $s_{t, k}$. Negative earning surprises are in Quantiles 1 through 5 , followed by zero surprises (Quantile 6), and positive surprises (Quantiles 7 though 11). The thresholds for the bins are set separately for each year to guarantee an equal number of non-Friday announcements for bins 1 through 5 and for bins 7 through 11. Since positive surprises are twice as common as negative surprises, bins 7-11 have twice as many observations as bins 1-5. Within each bin, we separate the Friday announcements from the non-Friday announcements. While this procedure has the advantage that it separately identifies the $10 \%$ to $17 \%$ of announcements with no earnings surprise in each year, we also consider the more traditional decile sorting procedure in the statistical analysis in the next subsection. The threshold for the bins are set each year to sort the non-Friday announcements into 10 equal groups. Since approximately $15 \%$ of the announcements are for zero surprises and these announcements fall into either decile 3 or 4 , deciles 3 through 5 are of unequal size.

Table IC reports the average earnings surprise $s_{t, k}$ within each quantile for the Friday and the non-Friday announcements. The within-quantile average earnings surprise is very similar for Friday and non-Friday announcements. The only exception is Quantile 1, where the average surprise for Friday announcements is $10 \%$ lower than for non-Friday announcements.

Immediate response. In Figure 1a we display the immediate response of stock returns,

$R_{t, k}^{(0,1)}$, to earnings surprises for Friday and non-Friday announcements. By construction, $R_{t, k}^{(0,1)}$ is the return from the close on the trading day before the earnings announcement to the close on the trading day after the earnings announcement for stock $k$ in quarter $t$. This measure captures the short-term response to announcements made during trading hours and announcements made after the market is closed. ${ }^{5}$ Compared to announcements on other days, the responsiveness of stock prices to earning surprises is substantially flatter for Friday announcements. Interestingly, most of the underreaction occurs for positive announcements: companies with positive announcements on Friday are significantly penalized initially. However, even for negative announcements there is less initial reaction on Friday: stock returns for quantiles 1 through 5 are less negative for Friday than for non-Friday announcements.

\section{Approximate location for Figures 1a-1b}

Delayed response. In Figure 1b we display the delayed reaction of stock returns, $R_{t, k}^{(2,75)}$, to the earnings announcements. In the non-Friday sample, positive earnings surprises are followed by positive returns in the period subsequent to the announcement, and the pattern is increasing in the magnitude of the surprise. Negative surprises are followed by negative 
delayed returns, but the magnitudes are smaller. Compared to non-Friday announcements, Friday announcements exhibit more delayed response. The pattern is strongest for the the most negative surprise, but is also present for the positive surprises.

\section{Approximate location for Figures 1c-1d}

\section{B. Top and bottom quantiles}

To quantify the graphical findings, we examine the stock response to very positive earnings news (top quantile) and very negative news (bottom quantile). We compare the immediate, delayed, and long-term sensitivity for Friday and non-Friday announcements. The OLS specification is

$$
R_{t, k}^{(h, H)}=\phi_{B}+\phi_{T-B} d_{t, k}^{t o p}+\phi_{B}^{F} d_{t, k}^{F}+\phi_{T-B}^{F} d_{t, k}^{t o p} d_{t, k}^{F}+\Gamma_{0} X_{t, k}+\Gamma_{1} d_{t, k}^{t o p} X_{t, k}+\varepsilon_{t, k}
$$

where $R_{t, k}^{(h, H)}$ denotes the abnormal stock returns for company $k$ in quarter $t$ between $h$ days before the announcement and $H$ days after the announcement. The sample includes only observations in the top quantile(s) $\left(d_{t, k}^{\text {top }}=1\right)$ or the bottom quantile(s) $\left(d_{t, k}^{\text {top }}=0\right)$. We focus on the coefficients $\phi_{T-B}$ and $\phi_{T-B}^{F}$. The coefficient $\phi_{T-B}$ measures the return to good news (top quantile) relative to bad news (bottom quantile) for non-Friday announcements. The coefficient $\phi_{T-B}^{F}$ captures the differential reaction for Friday relative to non-Friday announcements. Under the null hypothesis of constant (or no) investor distraction, $\phi_{T-B}^{F}$ should equal zero. Under the alternative hypothesis of higher distraction on Friday, $\phi_{T-B}^{F}$ should be negative for the immediate response $\left(R_{t, k}^{(0,1)}\right)$ and positive for the delayed response $\left(R_{t, k}^{(2,75)}\right)$. Distracted investors react less to news initially, and more afterwards.

Specification (5) allows the stock response to depend on a set of control variables $X_{t, k}$. For example, the responsiveness of stocks to earnings news may be correlated with company size if profit shocks are more permanent for larger firms. Similarly, the responsiveness may have increased with time if earnings disclosure regulation decreased the pre-announcement leakage of information. We include indicators for year of announcement, as well as 10 step functions for market capitalization. The indicators for market capitalization are constructed from $\log \left(p_{t, k} n_{t, k}\right)-\sum_{k=1}^{K} \log \left(p_{t, k} n_{t, k}\right) / K$, that is, log market capitalization for company $k$ in quarter $t$ minus the average market capitalization for other companies making announcements in the same quarter. We also include month indicators to control for differences in return sensitivity across quarters and within a quarter (early versus late releases). Finally, in some specifications we also control for earnings surprise volatility. Each year, we sort announcements into deciles using the company's earnings surprise standard deviation during the previous 4 
years, requiring a minimum of 4 observations. Each control (if included) is also interacted with the indicator variable for the top quantile (or top two quantiles). Standard errors are clustered by day of announcement to control for correlation of returns on the same day.

Immediate response. Table IIA presents specification (5) with the immediate abnormal return $R_{t, k}^{(0,1)}$ as dependent variable. Without controls (Column 1), the top-to-bottom average return for non-Friday announcements is $6.59 \%\left(\hat{\phi}_{T-B}=.0659\right)$. Compared to this value, the top-to-bottom return for a Friday announcement is (marginally) significantly smaller by .88 percentage points $\left(\hat{\phi}_{T-B}^{F}=-.0088\right)$. The top-minus-bottom return differential for Friday announcements is not significant with the standard set of controls $\left(\hat{\phi}_{T-B}^{F}=-.0059\right.$, Column 2 ) and marginally significant with additional controls for earnings surprise volatility $\left(\hat{\phi}_{T-B}^{F}=\right.$ -.0090 , Column 3). Using deciles to form the outermost groups, the coefficient $\phi_{T-B}^{F}$ is negative $\left(\hat{\phi}_{T-B}^{F}=-.0071\right.$, Column 4), but not significant.

\section{Approximate location for Table II}

In Columns 5-7 we replicate specification (5) on the observations in the top 2 and bottom 2 quantiles. (The variable $d_{t, k}^{\text {top }}$ is now an indicator for the top 2 quantiles.) The larger sample increases the precision of the estimates substantially. The top-to-bottom return differential for non-Friday announcements is $5.82 \%\left(\hat{\phi}_{T-B}=.0582\right.$, Column 5$)$. Relative to this differential, Friday announcements are associated with a $15.8 \%(0.0092 / 0.0582)$ lower immediate return response, an economically and statistically significant difference. This difference is of about the same size and significance level with the standard set of controls (not shown) and with the additional volatility controls $\left(\hat{\phi}_{T-B}^{F}=-.0086\right.$, Column 6$)$. The result is slightly larger if we use deciles to form the top and bottom two groups $\left(\hat{\phi}_{T-B}^{F}=-.0095\right.$, Column 7$)$.

Delayed response. In Table IIB we estimate specification (5) with the delayed abnormal performance $R_{t, k}^{(2,75)}$ as dependent variable. In the specification without controls (Column 1 ), the estimated post-earnings-announcement drift for non-Friday announcements, $\hat{\phi}_{T-B}$, is $5.14 \%$. (We measure drift as the difference in performance between the top and bottom earnings surprise quantiles). This magnitude is consistent with previous estimates (Bernard and Thomas, 1990). The drift for Friday announcements is significantly bigger by 4.62 percentage points $\left(\hat{\phi}_{T-B}^{F}=.0462\right)$, an $89.8 \%$ increase compared to other weekdays. The differential drift remains large and significant with both sets of controls (Columns 2 and 3) and is smaller and not significant using deciles $\left(\hat{\phi}_{T-B}^{F}=.0208\right.$, Column 4). The smaller differential drift obtained using deciles is consistent with Figure 1b, because the decile approach selects less extreme announcements in the bottom group which is responsible for most of the differential drift. ${ }^{6}$

In Columns 5-7 we replicate these results using the top two and bottom two groups. The 
drift is significantly larger on Friday both without controls (Column 5) and with controls (Column 6). In this latter specification, the Friday drift is $77.2 \%(.0350 / .0453)$ larger than drift on other weekdays. The differential drift on Friday is marginally significant using deciles to form the outermost groups $\left(\hat{\phi}_{T-B}^{F}=.0216\right.$, Column 7$)$.

To better understand the nature of this differential drift, we examine drift at various horizons for announcements on Friday and other weekdays in Figure 2. We measure drift as the difference in the average buy-and-hold abnormal returns between the top and bottom quantile. Most of the differential drift between Friday and non-Friday announcements does not emerge in the first 10 trading days following an announcement. Instead, differential drift becomes more readily apparent approximately 30 trading days after the announcement and continues to increase during the next 60 trading days. These patterns suggest that the neglected information is not incorporated right after the weekend, but in a slow process. One interpretation is that investors do not realize that they have ignored an announcement until they revisit their investment decisions for other reasons (e.g., subsequent news about the same company). Alternatively, investors might mistakenly believe that after missing the opportunity to trade on the day of or the day after the announcement there is no benefit to trading during the subsequent week. As Figure 2 shows, the timing of the increase in the differential drift is similar to the timing of the increase in drift for the baseline group (non-Friday announcements), which also appears largely after 30 trading days. This result is consistent with our preferred explanation that both drift and differential drift are due to the same underlying phenomenon, i.e., the delayed response following inattention to information.

\section{Approximate location for Figure 2}

Long-term response. In Table IIC we measure the impact on long-term returns $R_{t, k}^{(0,75)}$. For the six specifications used in Tables IIA and IIB, the top-bottom return differential on non-Fridays varies from $12.18 \%\left(\hat{\phi}_{T-B}=.1218\right.$, Column 2$)$ to $10.08 \%\left(\hat{\phi}_{T-B}=.1008\right.$, Column 7). The top-to-bottom differential response on Fridays $\hat{\phi}_{T-B}^{F}$ is positive, significantly so in some of the specifications. The long-term response to earnings news thus is somewhat larger for Friday than for non-Friday announcements.

Approximate location for Table II (cont.)

Summary. Stock prices respond less to Friday earnings surprises than to non-Friday earnings surprises in the immediate period $(0,1)$. In the later period $(2,75)$, stock prices respond more to Friday earning surprises, with smaller effects for the decile-based sorting procedure. Summing these two effects in the event window $(0,75)$, since the drift result is larger 
in magnitude, Friday announcements have a somewhat larger long-term effect. These patterns are generally consistent with the predictions of the model if more investors are inattentive to the information released on Friday. For Friday announcements, inattention leads to less initial response, followed by more delayed response, as investors become aware of the neglected information.

\section{Delayed response ratio}

We implement a unified test of the model, suggested by Corollary $1^{7}$, in Table IID. We compute the share of the total stock response to announcements $\left(R_{t, k}^{(0,75)}\right)$ that occurs with delay $\left(R_{t, k}^{(2,75)}\right)$. We then test whether the delayed response ratio (DRR) is higher for Friday announcements. There are two advantages of this methodology: (i) it controls for heterogeneity in the long-term reaction for Friday and non-Friday announcements (see Table IIC) by renormalizing with the long-term reaction; (ii) it offers an easily interpretable measure of the delay that provides a lower bound on the share of inattentive agents.

We compute numerator and denominator of DRR as the difference in the average cumulative abnormal returns between the top and bottom quantile. The measure for non-Friday announcements is

$$
D R R^{N F}=\frac{E\left[R_{k, t}^{(2,75)} \mid d_{t, k}^{t o p}=1, d_{t, k}^{F}=0\right]-E\left[R_{k, t}^{(2,75)} \mid d_{t, k}^{t o p}=0, d_{t, k}^{F}=0\right]}{E\left[R_{k, t}^{(0,75)} \mid d_{t, k}^{t o p}=1, d_{t, k}^{F}=0\right]-E\left[R_{k, t}^{(0,75)} \mid d_{t, k}^{t o p}=0, d_{t, k}^{F}=0\right]}=\frac{\phi_{T-B}^{(2,75)}}{\phi_{T-B}^{(0,75)}}
$$

where $\phi_{T-B}^{(2,75)}$ is the coefficient $\phi_{T-B}$ estimated in (5) with $R_{k, t}^{(2,75)}$ as dependent variable (and similarly for $\phi_{T-B}^{(0,75)}$ ) (Tables IIB and IIC). The standard errors are derived using the Delta method. In the specification without controls (Column 1), $42.44 \%$ of the top-to-bottom stock response is delayed $\left(D R R^{N F}=.4244\right)$. The results are remarkably similar with controls (Columns 2 and 3$)^{8}$, using deciles (Column 4), and using the top 2 and bottom 2 quantiles (Columns 5-7). For these different specifications, the average DRR lies between .40 and .45.

Similarly, we compute the delayed response ratio for Friday announcements:

$$
D R R^{F}=\frac{E\left[R_{k, t}^{(2,75)} \mid d_{t, k}^{t o p}=1, d_{t, k}^{F}=1\right]-E\left[R_{k, t}^{(2,75)} \mid d_{t, k}^{t o p}=0, d_{t, k}^{F}=1\right]}{E\left[R_{k, t}^{(0,75)} \mid d_{t, k}^{t o p}=1, d_{t, k}^{F}=1\right]-E\left[R_{k, t}^{(0,75)} \mid d_{t, k}^{t o p}=0, d_{t, k}^{F}=1\right]}=\frac{\phi_{T-B}^{(2,75)}+\phi_{T-B}^{F(2,75)}}{\phi_{T-B}^{(0,75)}+\phi_{T-B}^{F(2,75)}}
$$

In the benchmark specification (Column 1), $61.87 \%$ of the top-to-bottom response on Friday occurs with delay $\left(D R R^{F}=.6287\right)$. Compared to the delayed response ratio of .4244 on other weekdays, Fridays have an additional 19 percentage points of delayed reaction, an economically and statistically significant difference. The controls (Columns 2 and 3) and the top 2 and 
bottom 2 quantiles (Columns 5 through 6 ) have little effect on the results. In the specifications using deciles (Columns 4 and 7), the difference is marginally significant in one specification and highly significant in the other. Hence, even in specifications for which the initial reaction or the delayed reaction are not significantly different (Table IIA and IIB), there is a significant difference in the delayed response ratio for Friday and non-Friday announcements.

These results provide a lower bound for the share of distracted agents. Using Corollary 1.(iii), the estimates for $D R R^{N F}$ and $D R R^{F}$ imply that the share of distracted agents $\mu_{t}$ is larger than 0.4 for non-Friday announcements and larger than 0.6 for Friday announcements. Quantitatively, inattention appears to be substantial.

To estimate whether the findings depend more on the response to positive announcements (top quantile) or negative announcements (bottom quantile), we compute the delayed response ratio separately for the Top and Bottom quantiles. In unreported results, the numerator and denominator of $D R R$ are estimated using the difference between average returns in quantile $j$ and average returns in quantile 6. Friday announcements have higher delayed response ratios for both quantile 1 and quantile 11, compared to non-Friday announcements.

Summary. For non-Friday announcements, $40 \%$ to $45 \%$ of the stock response is delayed. For Friday announcements, this figure is between $54 \%$ and $62 \%{ }^{9}$ According to the model, these figures provide a lower bound for the share of distracted agents. The substantially higher delayed response ratio for Friday announcements is consistent with increased distraction postponing investor response on Friday. This pattern is observable both for positive and for negative surprises, although the results are less precise for negative surprises.

\section{Regressions including all announcements}

In the regressions above, we have restricted the attention to very positive and very negative earnings news. While this approach is simple and non-parametric, it does not take advantage of all available information. In order to use all the data, we impose identification restrictions on the relationship between earnings surprises and abnormal returns. Figure 1a indicates that the relationship between the earnings quantiles and the immediate stock response is approximately linear, with a differential slope for the Friday announcements. Linearity in the surprise quantile should not be confused with linearity in the surprise itself. As Figure 1d shows, the relationship between earnings surprises and the immediate stock response is monotonic but highly non-linear, with a clear S-shape (Kothari, 2001). While the relationship between earnings surprise quantiles and the delayed stock response is more noisy, Figure 1b indicates that this relationship is approximately linear as well. 
Following Hirshleifer, Lim, and Teoh (2007), we estimate the regression:

$$
R_{t, k}^{(h, H)}=\alpha+\beta S_{t, k}+\beta^{F} S_{t, k} d_{t, k}^{F}+\phi d_{t, k}^{F}+\Gamma_{0} X_{t, k}+\Gamma_{1} S_{t, k} X_{t, k}+\varepsilon_{t, k},
$$

where $S_{t, k}$ indicates the quantile corresponding to the earnings surprise, and hence $S=$ $1,2, \ldots, 11$, and $X_{t, k}$ denotes the same set of controls we use in subsections $\mathrm{B}$ and $\mathrm{C}$. The controls are present both in levels and interacted with the quantile function to allow for differential slopes of the function as a function of the controls. The coefficient $\beta$ captures the average response of stock return for as increase of one quantile in non-Friday announcements. The coefficient $\beta^{F}$ captures the differential response of Friday earnings announcements, compared to non-Friday announcements. Following the model, this specification assumes that, conditional on the controls, the response to Friday announcements is proportional to the response to non-Friday announcements.

Columns 1-3 in Table III present the results of specification (8) using the short-run returns $R^{(0,1)}$ as dependent variable. The specification in Column 1 without controls indicates that the short-run response for Friday announcement is $16.9 \%$ flatter than on other weekdays $(.0011 / .0065)$. The effect is precisely estimated and consistent with the finding of an $15.8 \%$ lower immediate response for the extreme quantiles (Table IIA). As we stated before, the assumption of linearity in the quantile embedded in this specification should not be confused with the assumption of linearity in the surprise itself. The $R^{2}$ of .0582 in the specification of Column 1 is substantially higher than the $R^{2}$ of .0090 for a specification that is piece-wise linear in the surprise (instead of in the quantiles) $R_{t, k}^{(0,1)}=\alpha+\alpha_{1} s_{t, k}+\phi^{F} s_{t, k} d_{t, k}^{F}+\gamma d_{t, k}^{F}+\varepsilon_{t, k} \cdot{ }^{10}$ We obtain very similar results with the standard set of controls (Column 2), and when we also control for earnings surprise volatility (not shown). Finally, the results are very similar when we use deciles instead of quantiles in specification (8) (Column 3). When we allow for a different response on each weekday, the immediate stock response is significantly different (lower) only for Friday announcements (not shown). The result of short-run attenuation for Friday announcements, therefore, is robust to different specifications and samples.

\section{Approximate location for Table III}

In Columns 4-6 in Table III we present the results of specification (8) using the long-term returns $R^{(2,75)}$ as dependent variable. The specification in Column 1 without controls indicates that the log-run response to Friday announcements is $56.2 \%$ larger than on other weekdays (.0027/.0048). This effect is also precisely estimated and consistent with the $77.2 \%$ increase for the extreme quantiles (Table IIB). The results are very similar with the standard set of controls (Column 2), when we also control for earnings surprise volatility (not shown), and 
when we use deciles instead of quantiles in specification (8) (Column 3). The result of larger drift for Friday announcements, therefore, is robust to different specifications and samples.

Summary. Friday announcements are associated with a $16.9 \%$ lower response of stock prices in the two days surrounding the announcement. These results are not sensitive to the introduction of controls or specification modifications, and are consistent with the results obtained using only the top and bottom quantile (Table IIA). We obtain a similarly robust result for the effect on the delayed stock response: it is 56.2 percent larger for Friday announcements. ${ }^{11}$ The decreased initial response and later stronger response fits the hypothesis that Friday and the weekend temporarily distract investors. ${ }^{12}$

\section{E. Portfolio returns}

The post-earnings announcement drift is substantially larger for Friday announcements than for non-Friday announcements. As an alternative measure of this differential drift, we present the returns to a portfolio that buys the Friday drift and sells the drift on other weekdays. This methodology mimics a feasible trading strategy designed to capture the specific type of inattention described in the model. It also demonstrates that the findings above are not induced by a pattern associated with a large number of announcements in a particular month or small number of months.

We analyze a monthly strategy from January 1995 to June 2006. The non-Friday drift portfolio for calendar month $t$ purchases companies that, in month $t-1$, made an announcement on a non-Friday in the top quantile; the portfolio sells short companies that, in month $t-1$, made an announcement on a non-Friday in the bottom quantile ${ }^{13}$. Therefore, the return for the non-Friday drift portfolio is $R_{N F}^{D}=R_{N F}^{11}-R_{N F}^{1}$, where the returns refer to calendar month $t$. The average non-Friday portfolio includes 168 stocks per month (113 long positions and 55 short positions). We compute monthly portfolio returns by equally weighting the relevant individual stock returns. ${ }^{14}$ Figure 3 shows year-by-year the average monthly return of this portfolio, which is between $-3 \%$ and $2 \%$.

\section{Approximate location for Figure 3}

We construct a Friday drift portfolio for month $t$ following a similar procedure except that we consider only companies that made an announcement on Friday during the previous month, $R_{F}^{D}=R_{F}^{11}-R_{F}^{1}$. The average Friday portfolio includes 15 stocks per month (8 long positions and 7 short positions). The average monthly return for this portfolio is higher, approximately $4 \%$ per month (Figure 3), but more volatile given the smaller number of companies making Friday announcements. Nevertheless, in 10 years out of 12 the Friday drift portfolio has higher 
returns than the non-Friday drift portfolio, and it performs substantially worse only in one year.

In Table IV, we evaluate a monthly portfolio that purchases (long position) the Friday drift portfolio and sells (short position) the non-Friday drift portfolio, $R_{F-N F}^{D}=R_{F}^{D}-R_{N F}^{D}=$ $R_{F}^{11}-R_{F}^{1}-\left(R_{N F}^{11}-R_{N F}^{1}\right)$. We control for market performance by regressing the series on the $C R S P$ value-weighted stock index, net of the one-month Treasury rate. The standard errors are corrected for heteroskedasticity and autocorrelation using the Newey-West estimator with 6 lags $^{15}$. The portfolio earns a significant monthly abnormal return of $3.84 \%$ (s.e. 1.34, Column 1). The estimated abnormal return increases somewhat if we include the size, book-to-market, and momentum factors (Column 2). While the magnitude of this effect seems implausibly large, we cannot reject a $1.8 \%$ monthly abnormal return, which is consistent with the estimated differential drift of 4.6 percentage points over 3 months (Table IIB).

\section{Approximate location for Table IV}

One explanation of these results is that Friday announcements in the bottom and top quantiles have more extreme surprises, and that more extreme announcements display more drift. To address this explanation, we match announcements on the earnings surprise. For each Friday announcement in the bottom (top) quantile, we find the five non-Friday announcements in the same quantile and month with the closest earnings surprise, subject to the constraint that the non-Friday surprises must be larger in absolute value. ${ }^{16}$ The latter requirement guarantees that the differential drift results are not driven by the presence of more extreme news in the Friday portfolio. The portfolio formed according to this procedure (Column 3) earns a monthly return of $5.84 \%$ that is somewhat larger than the return of the baseline portfolio (Column 2).

The abnormal returns are smaller (but still significant) if we compute the portfolios using the top 2 quantiles and the bottom 2 quantiles (Column 4). As in Table IIB, the differential Friday drift is smaller for these less extreme announcements. The portfolio return is lower $(2.14 \%)$, albeit still significant, if we include companies that made announcements in months $t-1$ or $t-2$, rather than just in month $t-1$ (Column 5). Finally, in Column 6 we determine the top and bottom groups by sorting the announcements into deciles instead of quantiles. The average return of the strategy, $2.77 \%$, is significant; while the return is lower than for the quantile-based procedure (Column 2), the significance level is higher. The lower average return is not surprising because the decile approach selects less extreme announcements in the bottom group.

Summary. We detect significantly higher portfolio returns from a drift strategy on Friday announcements than on non-Friday announcements. The differential return is generated largely in the first month after the announcement. The direction of the results is consistent with the 
findings in Table IIB, with larger point estimates.

\section{Volume response}

The immediate stock response to Friday earnings announcements is substantially lower than for non-Friday announcements. If this difference is caused by investor distraction, we expect a similar attenuation of trading volume in response to Friday news, because trading is the mechanism that causes prices to adjust. ${ }^{17}$ If the difference is instead driven by a higher dispersion of opinions for Friday announcements, we expect greater abnormal volume, rather than less, after Friday announcements.

The measure for abnormal volume is

$$
\Delta v_{t, k}^{(h, H)}=\sum_{u=h}^{H} \log \left(V_{t, k}^{u}\right) /(H-h+1)-\sum_{u=-20}^{-11} \log \left(V_{t, k}^{u}\right) / 10,
$$

where $V_{t, k}^{\tau}$ is the value of the shares traded on the $\tau$-th trading day after the earning announcement in quarter $t$ of company $k$. The measure $\Delta v_{t, k}^{(h, H)}$ is the percentage increase in volume around announcement date at horizon $(h, H)$, relative to baseline volume for stock $k$ in quarter $\tau$. In particular, $\Delta v_{t, k}^{(0,1)}$ is the immediate abnormal volume due to the announcement.

Graphical evidence. Figure 4 plots the average abnormal volume $\Delta v_{t, k}^{(h, H)}$ at various horizons. For non-Friday announcements, the abnormal volume increases to $47 \%$ on the day of the announcement, to $61 \%$ on the next trading day, and then it decays slowly. A week after the announcement, the trading volume is still $13 \%$ higher than normal. The abnormal volume for Friday announcements is $13 \%$ higher compared to non-Friday announcements on the announcement day, and $43 \%$ lower on the next trading day. During the subsequent days, abnormal volume is slightly higher for non-Friday announcements.

\section{Approximate location for Figure 4}

The main difference between Friday and non-Friday announcements occurs during the day of and the day after the announcement. Abnormal volume $\Delta v_{t, k}^{(0,1)}$ is substantially lower for Friday than for non-Friday announcements. ${ }^{18}$ Our interpretation of this finding is that the weekend distracts investors. This interpretation also suggests why the difference between Friday and non-Friday announcements mostly disappears by day $\tau+2$. Two offsetting forces are at work. On the one hand, some of the investors that have been distracted by the weekend are still not trading. On the other hand, other investors trade to respond to the underreaction after the weekend.

Regressions. We test whether the finding of lower abnormal volume $\Delta v_{t, k}^{(0,1)}$ for Friday 
announcements is affected by adding control variables. We run the OLS specification

$$
\Delta v_{t, k}^{(0,1)}=\alpha+\sum_{j \neq 6} \alpha_{j} d_{t, k}^{j}+\phi^{F} d_{t, k}^{F}+\Gamma X_{t, k}+\varepsilon_{t, k}
$$

The terms $d_{t, k}^{j}$ are indicators for earning surprises $s_{t, k}$ in the $j$-th quantile, with quantile 6 $\left(s_{k, t}=0\right)$ as the omitted category. The control variables $X_{t, k}$, as usual, are month, year, and size indicators, as well as earnings surprise volatility indicators in one specification. Without controls (Column 1 of Table V), the Friday coefficient is negative and significant, $\hat{\phi}^{F}=-.1109$. Compared to the average immediate volume increase on non-Fridays, .5416, the abnormal volume increase on Friday is $20.5 \%$ lower $(.1109 / .5416=.205)$. With controls (Column 2), the Friday effect is larger $\left(\hat{\phi}^{F}=-.1235\right)$.

In Column 3 we introduce firm fixed effects to control for any company-level difference in abnormal volume. Some of the Friday effect appears to be due to heterogeneity in abnormal volume among firms, but the remaining effect $\left(\hat{\phi}^{F}=-0.0436\right)$ is still large and significant. The $8.1 \%$ attenuation of abnormal volume for Friday announcements $(.0436 / .5416=.0081)$ is of the same order of magnitude as the $15 \%$ flattening of short-run stock returns (Tables IIA and III). We include firm fixed effects in the subsequent specifications. The results are very similar after controlling for earnings surprise volatility (Column 4), using decile indicators instead of quantile indicators (Column 5), and in the Homogeneous Sample (not shown).

\section{Approximate location for Table $\mathrm{V}$}

The attenuation of abnormal volume for Friday announcements could be explained by an unobserved variable that leads to lower aggregate market volume on Friday and Monday. To test for this explanation, we introduce a control for abnormal aggregate volume ${ }^{19}$. After introducing this control, the Friday effect is smaller and not statistically significant (Column 6). While this may indicate an omitted variable, this result is also consistent with the inattention hypothesis. Inattention predicts that, on Friday and Monday, volume should be lower in response to any information, and hence aggregate volume should also be lower.

Summary. Short-term abnormal volume is significantly lower for Friday earnings announcements, even after controlling for announcement quality, control variables, and firmspecific variation. The Friday effect in abnormal volume is of the same order of magnitude as the Friday effect in immediate returns. The effect is not statistically significant after controlling for aggregate volume. The volume results are consistent with the hypothesis that investors underreact initially to information released on Friday.

\section{Alternative explanations}


In this Section we consider four alternative explanations of the findings, information processing time, pre-announcement release, announcement delay, and firm heterogeneity. We also discuss an attention-related interpretation that is inconsistent with the data.

Information processing time. The mechanics of Friday and non-Friday announcements differ. First, Friday announcements in the 1970s were more likely to be made when the market was closed (Patell and Wolfson, 1982). Second, Friday announcements are followed by a twoday break in trading. For both reasons, investors have a different amount of time to process Friday announcements. However, these factors bias the analysis against finding underreaction. During our sample period, Friday announcements are less likely to be released after the market is closed (Bagnoli et al., 2005). (This explains why more of the volume response for Friday announcements occurs on the same day instead of the next day-Figure 4). Moreover, the two-day break in trading allows investors more time (not less) to assimilate new information.

Pre-announcement release. Companies release in advance the date of the earnings announcements. In the event of poor performance, companies may also issue earnings warnings. These pre-announcement releases could explain the lower immediate reaction of stock prices to Friday announcements. Assume that firms announcing on Friday are more likely to issue earnings warnings. Additionally, the decision to announce on Friday, itself, could be interpreted as a warning about earnings. Stock prices may respond before the official earnings announcement. Because forecasts are not always revised after these pre-announcements, the negative surprises constructed from the media forecast may overestimate the 'true' surprise to investors. This hypothesis can explain a lower short-term reaction of stock returns to negative surprises. However, it does not explain the attenuated short-term reaction for positive surprises. If anything, it predicts a stronger short-term response to positive announcements. This interpretation is also unable to explain differential drift. Further, we can directly test whether investors perceive more negative news before Friday announcements, conditional on the quantile of the surprise. Figure 1c displays stock returns for the horizon $(-30,-1)$ as a function of the quantiles of earnings surprises. In each of the outermost quantiles, the average pre-announcement returns are very similar for Friday and non-Friday announcements.

Announcement Delay. Stock prices decline before an earnings announcement if the announcement is delayed (Begley and Fischer, 1998; Bagnoli, Kross, and Watts, 2002). It is possible that Friday announcements are more likely to be late. Hence, part of the stock price reaction may occur before the earnings announcement. However, Bagnoli et al. (2002) also find that the response to earnings information is similar for on-time and late announcements. Late announcements, therefore, do not explain the flatter short-term response to Friday earnings announcements. In addition, delaying an announcement is essentially a pre-announcement warning. As we discussed above, there is no evidence of lower pre-announcement returns for 
negative earnings surprises announced on Friday (relative to other weekdays), after controlling for the earnings surprise quantiles (Figure 1c).

Firm heterogeneity. The attenuated immediate response on Friday could be due to unobserved heterogeneity. For example, the news about future profitability embedded in earnings announcements may be more transitory for firms making Friday announcements, or may reflect more divergence in opinions. Some of these explanations are not consistent with other findings. For example, if the Friday news were more temporary, we would expect less drift; if they reflected a higher divergence in opinions, we would expect a higher initial abnormal volume. While it is impossible to fully control for all forms of heterogeneity, we show that the results remain qualitatively unchanged after the introduction of time, company, and market capitalization controls.

Task overload. An attention-related interpretation is that investors on Monday are overburdened by information that has accumulated on their desks during the weekend and they find less time to react to Friday earnings announcements. However, aggregate volume is $10 \%$ lower on Monday, contrary to the hypothesis that traders are overwhelmed by this information.

\section{Conclusion}

We have compared the reaction to earnings announcements on Friday to the reaction on other weekdays. Friday announcements are characterized by a lower immediate, and a higher delayed, response. The delayed response as a percentage of the total response is $60 \%$ on Friday

and $40 \%$ on other weekdays. A portfolio that invests in the differential Friday drift earns substantial returns. We observe analogous results for volume.

The evidence supports the inattention hypothesis. On Friday, investors are distracted from work-related activities. Given limited attention, distractions cause underreaction to the earnings information. Eventually, investors recognize the mispricing and incorporate the information. Since a proxy for inattention increases the delayed reaction to earnings announcements, our findings indicate that underreaction to new information is an important source of postearnings announcement drift. 


\section{Appendix}

Equilibrium. In equilibrium, total demand must equal total supply for the risky asset or $\int_{0}^{1} \lambda_{t}^{i} d i=1$. After substituting for $\lambda_{t}^{i}$ in this expression, we solve for $P_{t}$ :

$$
P_{t}=\frac{b_{t} E_{t}^{\mu}\left[D_{t+1}+P_{t+1}\right]+\left(1-b_{t}\right) E_{t}^{1-\mu}\left[D_{t+1}+P_{t+1}\right]-a_{t}}{1+R}=\frac{\bar{E}_{t}\left[D_{t+1}\right]+\bar{E}_{t}\left[P_{t+1}\right]-a_{t}}{1+R}
$$

where $a_{t}=\left(\frac{\mu_{t}}{\gamma \sigma_{\mu, t, P+D}^{2}}+\frac{1-\mu_{t}}{\gamma \sigma_{1-\mu, t, P+D}^{2}}\right)^{-1}, \bar{E}_{t}=b_{t} E_{t}^{\mu}[]+.\left(1-b_{t}\right) E_{t}^{1-\mu}[$.$] and b_{t}=\frac{\mu_{t}}{\gamma \sigma_{\mu, t, P+D}^{2}} a_{t}$. Recursively solving forward expression and also imposing the relevant transversality condition $\lim _{T \rightarrow \infty}\left(\bar{E}_{t} \bar{E}_{t+1} \ldots \bar{E}_{t+T+1}\left[P_{t+T+2}\right]\right) /(1+R)^{T+2}=0$ yields

$$
P_{t}=\frac{\bar{E}_{t}\left[D_{t+1}\right]-a_{t}}{1+R}+\sum_{s=1}^{\infty} \frac{\bar{E}_{t} \bar{E}_{t+1} \ldots \bar{E}_{t+s}\left[D_{t+s+1}-a_{t+s}\right]}{(1+R)^{s+1}} .
$$

Since the information available at time $t$ is uninformative regarding $D_{t+s+1}, \forall s>0$, we know that $\bar{E}_{t+1} \bar{E}_{t+2} \ldots \bar{E}_{t+s}\left[D_{t+s+1}\right]=\delta$. Since future signals about dividends are unforecastable, the strategic release of future signals is unforecastable as well. As long as perceived variances are time-invariant (verified below), $E_{t+s-1}^{\mu}\left[a_{t+s}\right]=E_{t+s-1}^{1-\mu}\left[a_{t+s}\right]=\bar{a}$ where $\bar{a}=\eta a\left(\mu_{h}\right)+$ $(1-\eta) a\left(\mu_{l}\right)$ and $\eta=\operatorname{prob}\left(\mu_{t+s}=\mu_{h}\right)$. Consequently, $\bar{E}_{t} \bar{E}_{t+1} \ldots \bar{E}_{t+s}\left[a_{t+s}\right]=\bar{a}$ and the formula for the equilibrium price follows.

Time-invariant perceived variances. We show that $\sigma_{\mu, t, P+D}^{2}$ and $\sigma_{1-\mu, t, P+D}^{2}$ do not depend on $t$. First, we solve for $\sigma_{\mu, t, P+D}^{2}$ :

$$
\begin{aligned}
\sigma_{\mu, t, P+D}^{2} & =E_{t}^{\mu}\left[\left(P_{t+1}+D_{t+1}-E_{t}^{\mu}\left[P_{t+1}+D_{t+1}\right]\right)^{2}\right] \\
& =E_{t}^{\mu}\left[\left(\frac{\left(1-b_{t+1}\right) s_{t+1}-a_{t+1}-\left(E_{t}^{\mu}\left[\left(1-b_{t+1}\right) s_{t+1}\right]-\bar{a}\right)}{1+R}+s_{t}+\varepsilon_{t+1}\right)^{2}\right] \\
& =\left(\frac{1}{1+R}\right)^{2} \sigma_{(1-b) s-a}^{2}+\sigma_{s}^{2}+\sigma_{\varepsilon}^{2}
\end{aligned}
$$

Similarly, $\sigma_{1-\mu, t, P+D}^{2}=\left(\frac{1}{1+R}\right)^{2} \sigma_{(1-b) s-a}^{2}+\sigma_{\varepsilon}^{2}$. If the strategic behavior of managers is timeinvariant (proposition 2), neither perceived variance expression depends on $t$.

Comparative statics for $a_{t}$ and $b_{t}$. Let $k=(1+R)^{-2} \sigma_{(1-b) s-a}^{2}+\sigma_{\varepsilon}^{2}$. We substitute the expressions for $\sigma_{\mu, P+D}^{2}, \sigma_{1-\mu, P+D}^{2}$, and $k$ into the definition of $a_{t}$ and rearrange to obtain.

$$
a_{t}=\gamma\left(k^{2}+k \sigma_{s}^{2}\right)\left(k+\sigma_{s}^{2}\left(1-\mu_{t}\right)\right)^{-1}
$$

Since $k>0$, it follows that $a_{h}>a_{l}$. Using a similar procedure,

$$
b_{t}=k \mu_{t}\left(k+\sigma_{s}^{2}\left(1-\mu_{t}\right)\right)^{-1}
$$

which implies that $b_{h}>b_{l}$ and $b_{t}\left(\mu_{t}=0\right)=0$. 
Proof of Proposition 1. For part (i) we start with the definition of $I R_{t}$,

$$
\begin{aligned}
E_{t}\left[I R_{t}\right] & =E_{t}\left[Z_{t}-E_{t-1}\left[Z_{t}\right]-\left(D_{t}-E_{t-1}\left[D_{t}\right]\right)\right]=P_{t}-E_{t-1}\left[P_{t}\right]= \\
& =-\frac{a_{t}-\bar{a}}{1+R}+\frac{\left(1-b_{t}\right) s_{t}-E_{t-1}\left[\left(1-b_{t}\right) s_{t}\right]}{1+R}=\frac{\bar{a}-a_{t}}{1+R}+\frac{\sigma_{b s}}{1+R}+\frac{1-b_{t}}{1+R} s_{t} .
\end{aligned}
$$

The remainder of the proof follows from from $b_{h}>b_{l}$ and $b_{t}\left(\mu_{t}=0\right)=0$. For part (ii) we start with the definition of $E_{t}\left[Z_{t+1}\right]$.

$$
\begin{aligned}
E_{t}\left[Z_{t+1}\right] & =E_{t}\left[P_{t+1}+D_{t+1}-(1+R) P_{t}\right] \\
& =-\frac{E_{t}\left[b_{t+1} s_{t+1}\right]}{1+R}+s_{t}+a_{t}-\left(1-b_{t}\right) s_{t}=a_{t}-\frac{\sigma_{b s}}{1+R}+b_{t} s_{t} .
\end{aligned}
$$

This implies $E_{t}\left[D R_{t}\right]=E_{t}\left[Z_{t+1}\right]-E_{t-1}\left[Z_{t+1}\right]=a_{t}-\bar{a}+b_{t} s_{t}-E_{t-1}\left[b_{t} s_{t}\right]=a_{t}-\bar{a}-\sigma_{b s}+b_{t} s_{t}$. The remainder of the proof follows from $b_{h}>b_{l}$ and $b_{t}\left(\mu_{t}=0\right)=0$. For part (iii) we rewrite that $Z_{t+1, t-1}$ as $Z_{t+1}+(1+R) Z_{t}$. We substitute this expression for $Z_{t+1, t-1}$ into the expression for $E_{t}\left[L R_{t+1}\right]$ (in the text) to obtain

$$
\begin{aligned}
E_{t}\left[L R_{t+1}\right] & =\left[\left(E_{t}\left[Z_{t}\right]-E_{t-1}\left[Z_{t-1}\right]\right)-\left(E_{t}\left[D_{t}\right]-E_{t-1}\left[D_{t}\right]\right)\right]+\frac{E_{t}\left[Z_{t+1}\right]-E_{t-1}\left[Z_{t+1}\right]}{1+R} \\
& =E_{t}\left[I R_{t}\right]+\frac{E_{t}\left[D R_{t}\right]}{1+R}
\end{aligned}
$$

The remainder of the proof follows from this expression for $E_{t}\left[L R_{t+1}\right]$ and parts (i) and (ii).

Proof of Corollary 1. Part (i) follows from the expressions for $E_{t}\left[D R_{t}\right]$ and $E_{t}\left[L R_{t+1}\right]$ in the proof of proposition 1. Part (ii) follows from $b_{h}>b_{l}$ and $b_{t}\left(\mu_{t}=0\right)=0$. Part (iii) follows from $R>0$ and the definition of $b_{t}$ because $\sigma_{1-\mu, t, P+D}^{2}$ is necessarily smaller than $\sigma_{\mu, t, P+D}^{2}$.

Proof of Proposition 2. Part (i) is discussed in the body of the paper. We prove part (ii). The problem of the short-term manager is equivalent to solving $\max _{\mu_{t} \in\left\{\mu_{h}, \mu_{l}\right\}}-a_{t}-b_{t} s_{t}$. Substituting in the values of $a_{t}$ and $b_{t}$, we obtain

$$
\max _{\mu_{t} \in\left\{\mu_{h}, \mu_{l}\right\}}\left(-\gamma-\frac{\mu_{t} s_{t}}{k+\sigma_{s}^{2}}\right)\left(\frac{\mu_{t}}{k+\sigma_{s}^{2}}+\frac{1-\mu_{t}}{k}\right)^{-1}
$$

where $k=(1+R)^{-2} \sigma_{b s-a}^{2}+\sigma_{\varepsilon}^{2}>0$. Announcing on a high-distraction day is optimal iff

$$
\left(-\gamma-\frac{\mu_{h} s_{t}}{k+\sigma_{s}^{2}}\right)\left(\frac{\mu_{h}}{k+\sigma_{s}^{2}}+\frac{1-\mu_{h}}{k}\right)^{-1} \geq\left(-\gamma-\frac{\mu_{l} s_{t}}{k+\sigma_{s}^{2}}\right)\left(\frac{\mu_{l}}{k+\sigma_{s}^{2}}+\frac{1-\mu_{l}}{k}\right)^{-1}
$$

Multiplying the terms together and simplifying leads to $\mu_{h} s_{t}-\gamma \sigma_{s}^{2} \mu_{l} \leq \mu_{l} s_{t}-\gamma \sigma_{s}^{2} \mu_{h}$, and finally to $s_{t} \leq-\sigma_{s}^{2} \gamma$, the desired condition. Given this threshold rule, $E\left[s_{t} \mid \mu_{t}=\mu_{h}\right]<0$ and $E\left[s_{t} \mid \mu_{t}=\mu_{l}\right]>0$ follow immediately. Hence, $E\left[s_{t} \mid \mu_{t}=\mu_{h}\right]<E\left[s_{t} \mid \mu_{t}=\mu_{l}\right]$. The relationship $E\left[I R_{t} \mid \mu_{t}=\mu_{h}\right]<E\left[I R_{t} \mid \mu_{t}=\mu_{l}\right]$ follows from

$$
E\left[I R_{t} \mid \mu_{t}=\mu_{h}\right]-E\left[I R_{t} \mid \mu_{t}=\mu_{l}\right]=\frac{a_{l}-a_{h}}{1+R}+\frac{1-b_{h}}{1+R} E\left[s_{t} \mid \mu_{t}=\mu_{h}\right]-\frac{1-b_{l}}{1+R} E\left[s_{t} \mid \mu_{t}=\mu_{l}\right]
$$

because $a_{l}-a_{h}<0, E\left[s_{t} \mid \mu_{t}=\mu_{h}\right]<0$, and $E\left[s_{t} \mid \mu_{t}=\mu_{l}\right]>0$. 


\section{Notes}

${ }^{1}$ Given the information and trading structure of the model, the behavior of the stock return remains unchanged if we assume that the distracted investors observe the signal one period after announcement or if we assume that the distracted investors never observe the signal. This result is driven by the inability to trade between the announcement of the signal at $t$ and the dividend payment at $t+1$, when the information in the signal becomes irrelevant.

${ }^{2}$ The results are similar if we use the average forecast as a measure of consensus forecast or if we use analyst forecasts made within a shorter time horizon (15 days).

${ }^{3}$ The measure of earnings per share in $I / B / E / S$ reflects capital structure changes. In order to make the units of the earning announcements and forecasts comparable with the units of the price data $P_{t, k}$, we apply the adjustment provided by $I / B / E / S$. Since the adjustment factor is stored as a truncated number, the resulting variables $e_{t, k}$ and $\hat{e}_{t, k}$ have fractional cents. We round the earning per share measure $e_{t, k}$ to the nearest cent and the earnings forecast $\hat{e}_{t, k}$ to the nearest half cent.

${ }^{4}$ The results in the paper are similar if we use raw returns or net returns.

${ }^{5}$ Since the time stamp for each announcement is not available in $I / B / E / S$ or $C O M$ PUSTAT, we cannot separate announcements made during trading hours from those made after close.

${ }^{6}$ The bottom quantile contains 8,428 observations, while the bottom decile contains 15,045 observations.

${ }^{7}$ We thank Owen Lamont for suggesting this approach.

${ }^{8}$ In the specifications with controls, we estimate the differential response ratio at the average value for each the controls.

${ }^{9}$ The delayed response ratios for the Homogenous sample are similar to those for the whole sample.

${ }^{10}$ Bagnoli et al. (2005) use a piece-wise linear specification and find that the short-run response to Friday announcements is muted for negative surprises.

${ }^{11}$ In unreported regressions using the Homogeneous sample, there is less short-run attenuation and more differential drift for Friday announcements, compared to the whole sample.

${ }^{12}$ We would like to test whether the decrease in the initial response occurs on Friday, 
before the weekend, or on Monday, after the weekend. However, this test requires that the fraction of announcements taking place after market close be similar for Friday and non-Friday announcements. Unfortunately, in recent years Friday announcements are significantly less likely to occur after market close (Bagnoli et al., 2005), making a direct comparison impossible.

${ }^{13} \mathrm{An}$ announcement is part of the portfolio in month $t$ if the second trading day after the announcement is in month $t-1$. We compute the breakpoints for the 11 quantiles with the procedure described previously, except that we use the breakpoints from the prior calendar year. This approach guarantees that the trading strategy does not use any forward-looking information. If there are no stocks for a constituent portfolio, then that month is excluded from the performance analysis.

${ }^{14}$ Value-weighting the returns within the constituent portfolios yields similar results.

${ }^{15}$ The results do not change qualitatively if the lag length for the Newey-West standard errors is 12 .

${ }^{16}$ If there are fewer than five non-Friday announcements with more extreme earnings surprises than a specific Friday announcement, the returns of the stocks with these nonFriday announcements are overweighted appropriately. Friday announcements that can not be matched to at least one non-Friday announcement with a more extreme earnings surprise are excluded from the analysis.

${ }^{17}$ This prediction does not follow from the model in Section I because the model has no natural definition of trading volume.

${ }^{18}$ The measures $\Delta v_{t, k}^{(0,0)}$ and $\Delta v_{t, k}^{(1,1)}$ need to be considered together because the share of announcements after market close is lower on Friday.

${ }^{19} \mathrm{We}$ measure aggregate volume as the equal-weighted average across firms of the number of shares traded, divided by shares outstanding. We generate the abnormal aggregate volume $\Delta v_{t, A}^{(0,1)}$ using equation (9). 


\section{REFERENCES}

Bagnoli, Mark, Michael B. Clement, and Susan G. Watts. "Around-the-Clock Media Coverage and The Timing of Earnings Announcements", mimeo, 2005.

Bagnoli, Mark, William Kross, and Susan G. Watts. "The Information in Management's Expected Earnings Report Date: A Day Late, a Penny Short", Journal of Accounting Research, Vol. 40, 1275-1296, 2002.

Baker, Malcolm, Richard Ruback, and Jeffrey Wurgler. "Behavioral Corporate Finance: A Survey." In The Handbook of Corporate Finance: Empirical Corporate Finance, edited by Espen Eckbo. New York: Elsevier/North Holland, forthcoming.

Barber, Brad M. and Terrance Odean. "All that Glitters: The Effect of Attention and News on the Buying Behavior of Individual and Institutional Investors", Review of Financial Studies, forthcoming.

Barberis, Nicholas, Andrei Shleifer, and Robert Vishny. "A model of investor sentiment", Journal of Financial Economics, Vol. 49, 307-343, 1998.

Begley, Joy and Paul Fischer. "Is there Information in an Earnings Announcement Delay?", Review of Accounting Studies, Vol. 3, 347-364, 1998.

Bernard, Victor L. and Jacob K. Thomas. "Post-Earnings-Announcement Drift: Delayed Price Response or Risk Premium?", Journal of Accounting Research, Vol. 27, 1-36, 1989.

Bernard, Victor L. and Jacob K. Thomas. "Evidence That Stock Price Do Not Fully Reflect the Implications of Current Earnings For Future Earnings", Journal of Accounting and Economics, Vol. 13, 305-340, 1990.

Chan, Louis, Narasimham Jegadeesh, and Josef Lakonishok. "Momentum Strategies", Journal of Finance, Vol. 51, 1681-1713, 1996.

Cohen, Lauren, and Andrea Frazzini. "Economic Links and Predictable Returns", Journal of Finance, forthcoming.

Damodaran, Aswath. "The Weekend Effect in Information: A Study of Earnings and Dividend Announcements", Review of Financial Studies, Vol. 4, 607-623, 1989.

Daniel, Kent, David Hirshleifer, and Avanidhar Subrahmanyam. "Investor Psychology and Security Market Under-and Overreactions", Journal of Finance, Vol. 53, 1839-1885, 1998. 
DellaVigna, Stefano and Ulrike Malmendier. "Contract Design and Self-Control: Theory and Evidence", Quarterly Journal of Economics, Vol. 119, 353-402, 2004.

DellaVigna, Stefano and Joshua M. Pollet. "Demographics and Industry Returns", American Economic Review, Vol. 97, 1167-1702, 2007.

DeLong, J. Bradford, Andrei Shleifer, Lawrence H. Summers, Robert J. Waldmann. "Noise Trader Risk in Financial Markets", Journal of Political Economy, Vol. 98, 703-738, 1990.

Dyck, Alexander and Luigi Zingales. "The Media and Asset Prices", mimeo, 2003.

Frazzini, Andrea. "The Disposition Effect and Under-Reaction to News", Journal of Finance, Vol. 61, 2017-2046, 2006.

Gabaix, Xavier and David Laibson. "Shrouded Attributes and Information Suppression in Competitive Markets", Quarterly Journal of Economics, Vol. 121, 505-540, 2006.

Gabaix, Xavier, David Laibson, Guillermo Moloche and Stephen Weinberg. "The Allocation of Attention: Theory and Evidence", American Economic Review, Vol. 96, 1043-1068, 2006.

Grinblatt, Mark and Bing Han. "Prospect Theory, Mental Accounting, and Momentum", Journal of Financial Economics, Vol. 78, 311-333, 2005.

Hirshleifer, David, Sonya Lim and Siew Hong Teoh. "Driven to Distraction: Extraneous Events and Underreaction to Earnings News", mimeo, 2007.

Hirshleifer, David and Siew Hong Teoh. "Limited Attention, Information Disclosure, and Financial Reporting", Journal of Accounting and Economics, Vol. 36, 337-386, 2003.

Hong, Harrison and Jeremy Stein. "A Unified Theory of Underreaction, Momentum Trading, and Overreaction in Asset Markets", Journal of Finance, Vol. 54, 2143-2184, 1999.

Huberman, Gur, and Tomer Regev. "Contagious Speculation and a Cure for Cancer: A Nonevent that Made Stock Prices Soar", Journal of Finance, Vol. 56, 387-396, 2001.

Jegadeesh, Narasimhan, and Sheridan Titman. "Returns to Buying Winners and Selling Losers: Implications For Stock Market Efficiency", Journal of Finance, Vol. 48, 65-91, 1993.

Keim, Donald and Robert Stambaugh. "A Further Investigation of the Weekend Effect in Stock Returns", Journal of Finance, Vol. 39, 819-835, 1984.

Kothari, S.P. "Capital Markets Research in Accounting", Journal of Accounting and Economics, Vol. 31, 105-231, 2001. 
Patell, James M. and Mark A. Wolfson. "Good News, Bad News and the Intraday Timing of Corporate Disclosures", The Accounting Review, Vol. 57, 509-527, 1982.

Peng, Lin and Wei Xiong. "Investor Attention, Overconfidence and Category Learning", Journal of Financial Economics, Vol. 80, pp. 563-602, 2006.

Penman, Stephen H. "The Distribution of Earnings News Over Time and Seasonalities in Aggregate Stock Returns", Journal of Financial Economics, Vol. 18, 199-228, 1987.

Shleifer, Andrei. Inefficient Markets: An Introduction to Behavioral Finance. Clarendon Lectures in Economics. Oxford and New York: Oxford University Press, 2000. 

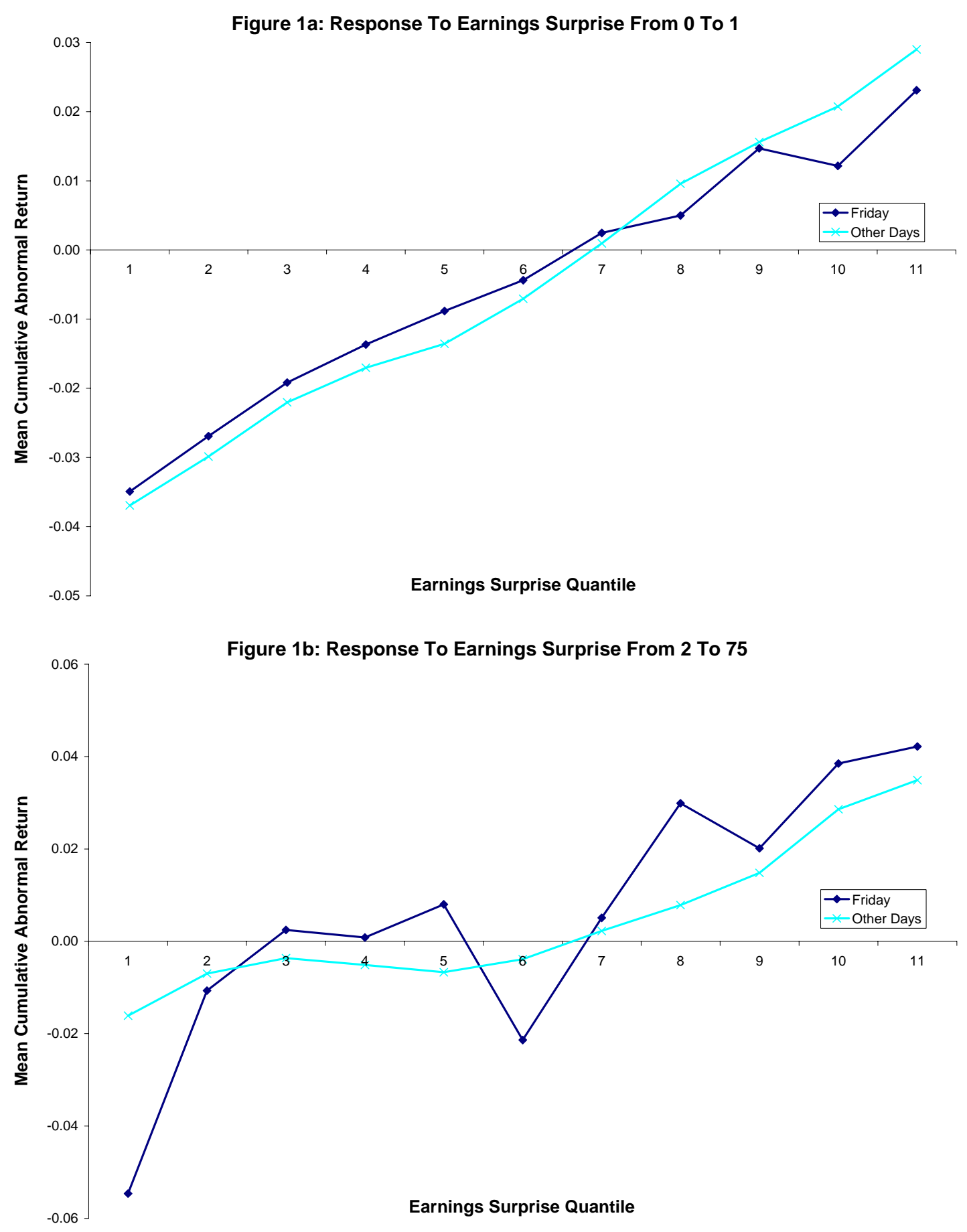

Figures 1a-1b. Stocks in CRSP are matched to quarterly earnings announcements in I/B/E/S from January 1995 until June 2006 . In event time, day 0 is the day of the announcement. The cumulative abnormal return for each stock is the raw buy-and-hold return adjusted using the estimated beta from market model. The earnings surprise for an announcement is the difference between actual earnings for the quarter recorded by I/B/E/S and the median analyst forecast included in the I/B/E/S detail file during the 30 days before the quarterly earnings announcement scaled by the stock price 5 trading days before the announcement. Quantiles 1 through 5 contain earnings announcements for five quintiles of negative earnings surprises and quantiles 7 through 11 contain earnings surprises for five quintiles of positive earnings surprises. Quantile number 6 contains all announcements with an earnings surprise equal to zero. Since the number of negative earnings surprises, of positive earnings surprises, and of surprises equal to zero are unequal, the number of observations in each quantile differ. The breakpoints for the quantiles are determined separately for each year and announcements made on Saturday or Sunday are excluded from the sample. 
Figure 1c: Response To Earnings Surprise From -30 To -1

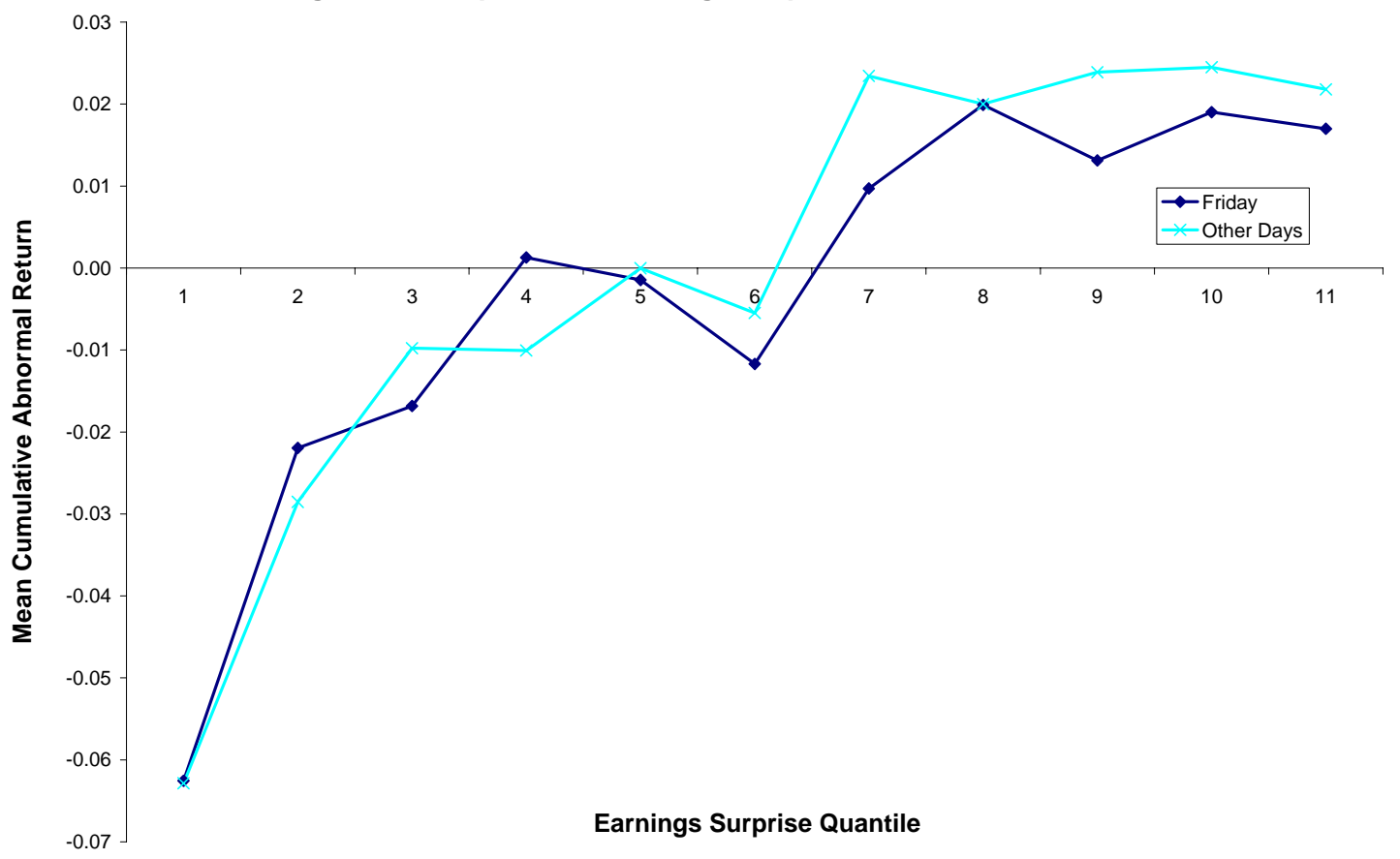

Figure 1d: Nonlinear Form of the Response to Earnings Surprise From 0 to 1

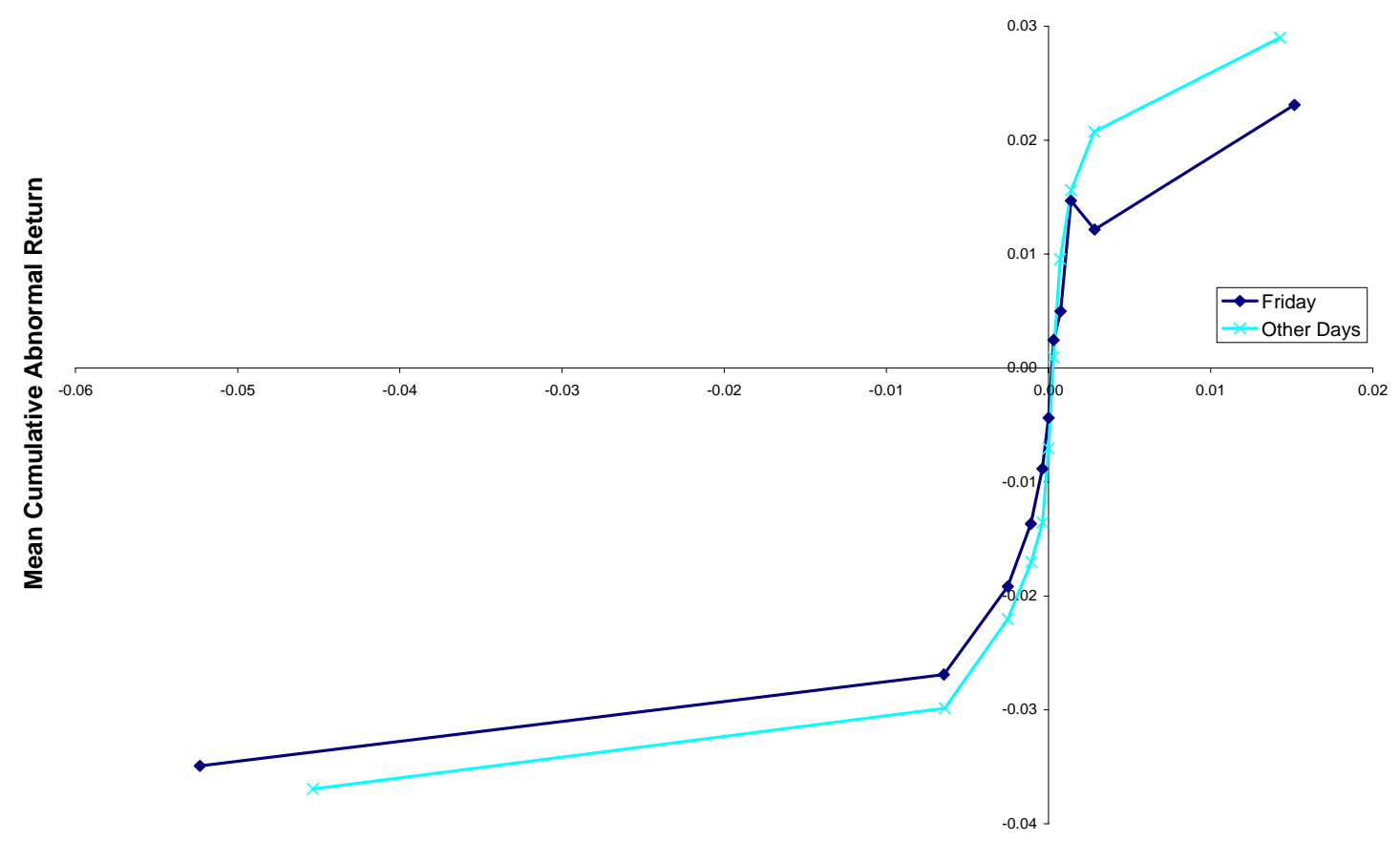

Mean Earnings Surprise For Each Quantile

Figures 1c-1d. Stocks in CRSP are matched to quarterly earnings announcements in I/B/E/S from January 1995 until June 2006 . In event time, day 0 is the day of the announcement. The cumulative abnormal return for each stock is the raw buy-and-hold return adjusted using the estimated beta from market model. The earnings surprise for an announcement is the difference between actual earnings for the quarter recorded by I/B/E/S and the median analyst forecast included in the I/B/E/S detail file during the 30 days before the quarterly earnings announcement scaled by the stock price 5 trading days before the announcement. Quantiles 1 through 5 contain earnings announcements for five quintiles of negative earnings surprises and quantiles 7 through 11 contain earnings surprises for five quintiles of positive earnings surprises. Quantile number 6 contains all announcements with an earnings surprise equal to zero. Since the number of negative earnings surprises, of positive earnings surprises, and of surprises equal to zero are unequal, the number of observations in each quantile differ. The breakpoints for the quantiles are determined separately for each year and announcements made on Saturday or Sunday are excluded from the sample. 
Figure 2: Performance of Drift at Different Horizons

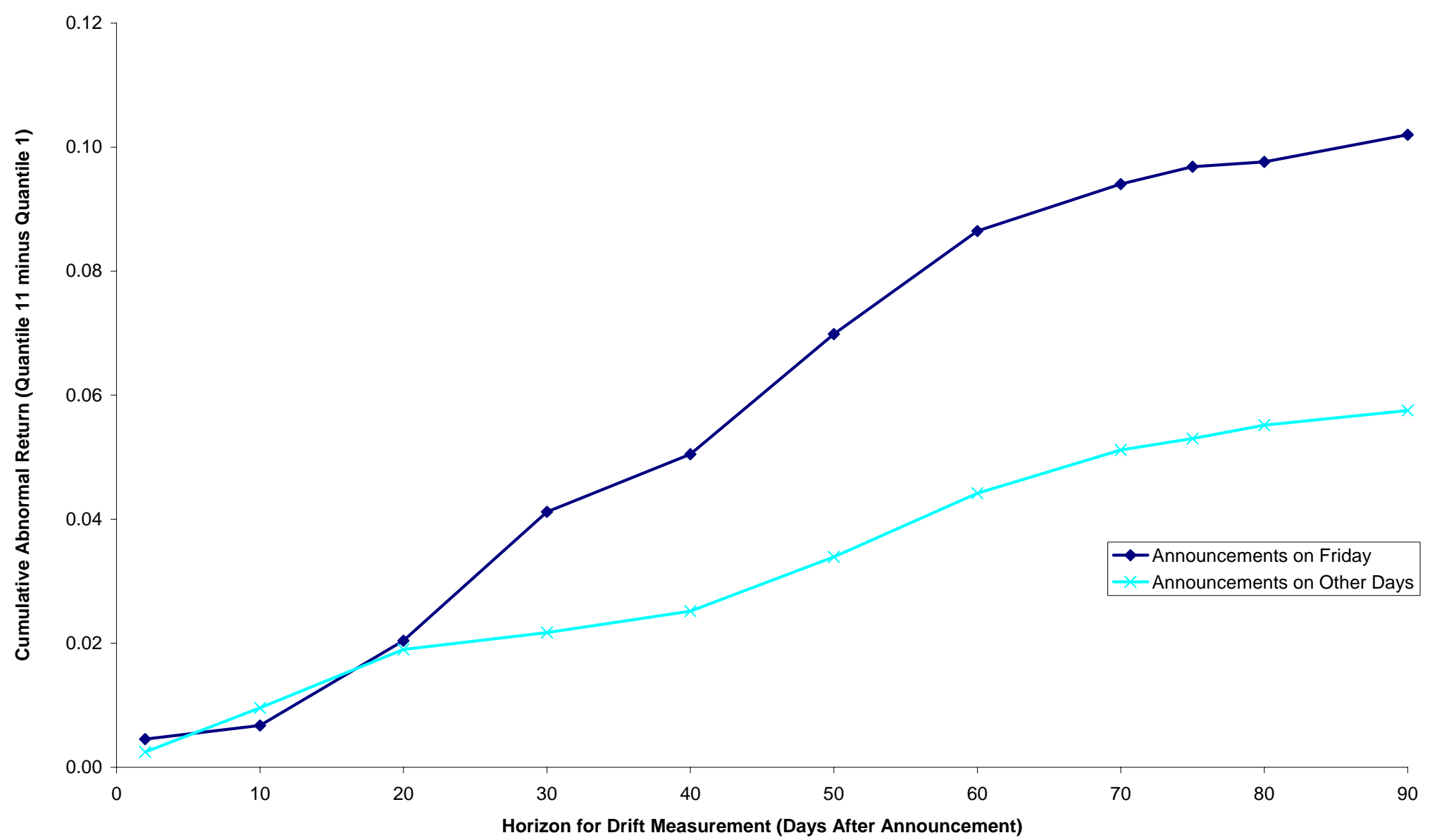

Figure 2. Stocks in CRSP are matched to quarterly earnings announcements in I/B/E/S from January 1995 until June 2006. In event time, day 0 is the day of the announcement. The cumulative abnormal return for each stock is the raw buy-and-hold return adjusted using the estimated beta from market model. The earnings surprise for an announcement is the difference between actual earnings for the quarter recorded by I/B/E/S and the median analyst forecast included in the I/B/E/S detail file during the 30 days before the quarterly earnings announcement scaled by the stock price 5 trading days before the announcement. Quantiles 1 through 5 contain earnings announcements for five quintiles of negative earnings surprises and quantiles 7 through 11 contain earnings surprises for five quintiles of positive earnings surprises. Quantile number 6 contains all announcements with an earnings surprise equal to zero. The breakpoints for the quantiles are determined separately for each year and announcements made on Saturday or Sunday are excluded from the sample. The measure for post-earnings announcement drift for horizon $\mathrm{h}$ is the average cumulative abnormal return from day 2 to day $\mathrm{h}$ for quantile 11 minus the average cumulative abnormal return from day 2 to day $h$ quantile 1. 


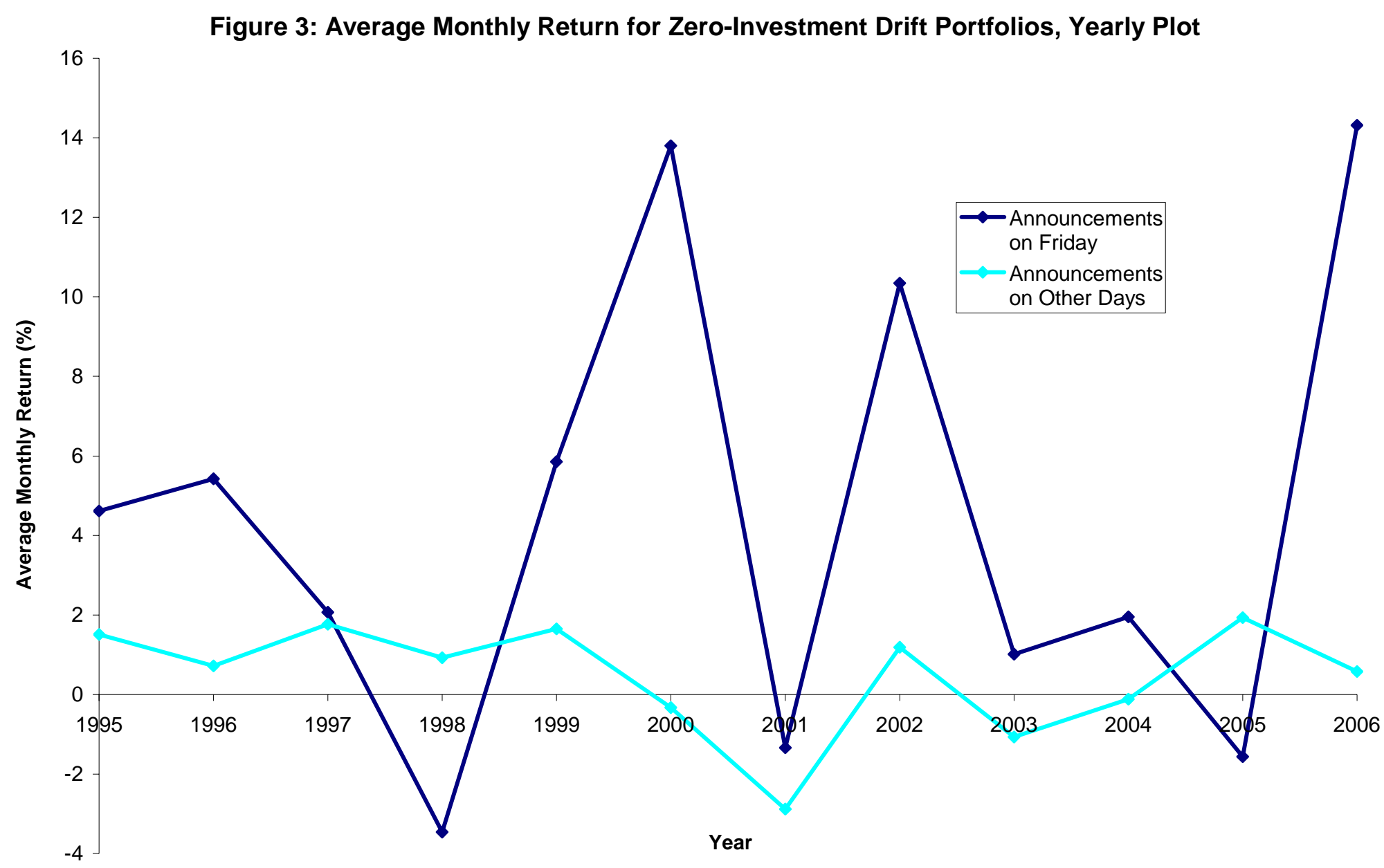

Figure 3. For each year we report the average monthly return for the zero-investment portfolio for announcements on Friday and for announcements on other weekdays. Stocks in CRSP are matched to quarterly earnings announcements in $\mathrm{I} / \mathrm{B} / \mathrm{E} / \mathrm{S}$ from January 1995 until June 2006 . The earnings surprise for an announcement is the difference between actual earnings for the quarter recorded by I/B/E/S and the median analyst forecast included in the I/B/E/S detail file during the 30 days before the quarterly earnings announcement scaled by the stock price 5 trading days before the announcement. Quantiles 1 through 5 contain earnings announcements for five quintiles of negative earnings surprises and quantiles 7 through 11 contain earnings surprises for five quintiles of positive earnings surprises. Quantile number 6 contains all announcements with an earnings surprise equal to zero. Since the number of negative earnings surprises, of positive earnings surprises, and of surprises equal to zero are unequal, the number of observations in each quantile differ. Announcements made on Saturday or Sunday are excluded from the sample. The sorting mechanism uses the breakpoints for the quantiles determined by non-Friday announcements during the previous calendar year. At the end of calendar month t-1 the zero-investment drift portfolio for month t using Friday announcements (respectively, using announcements on other weekdays) is created as follows. The strategy purchases stocks with earnings surprise announcements in the highest quantile and sells stocks with earnings surprises in the lowest quantile in month $\mathrm{t}-1$. For a stock to be included in the one-month holding period strategy for calendar month $\mathrm{t}$, the second trading day after the announcement must be in month $\mathrm{t}-1$. If there are no stocks in a constituent portfolio, then that month is excluded from the analysis. Returns are equally-weighted within the constituent portfolios. 


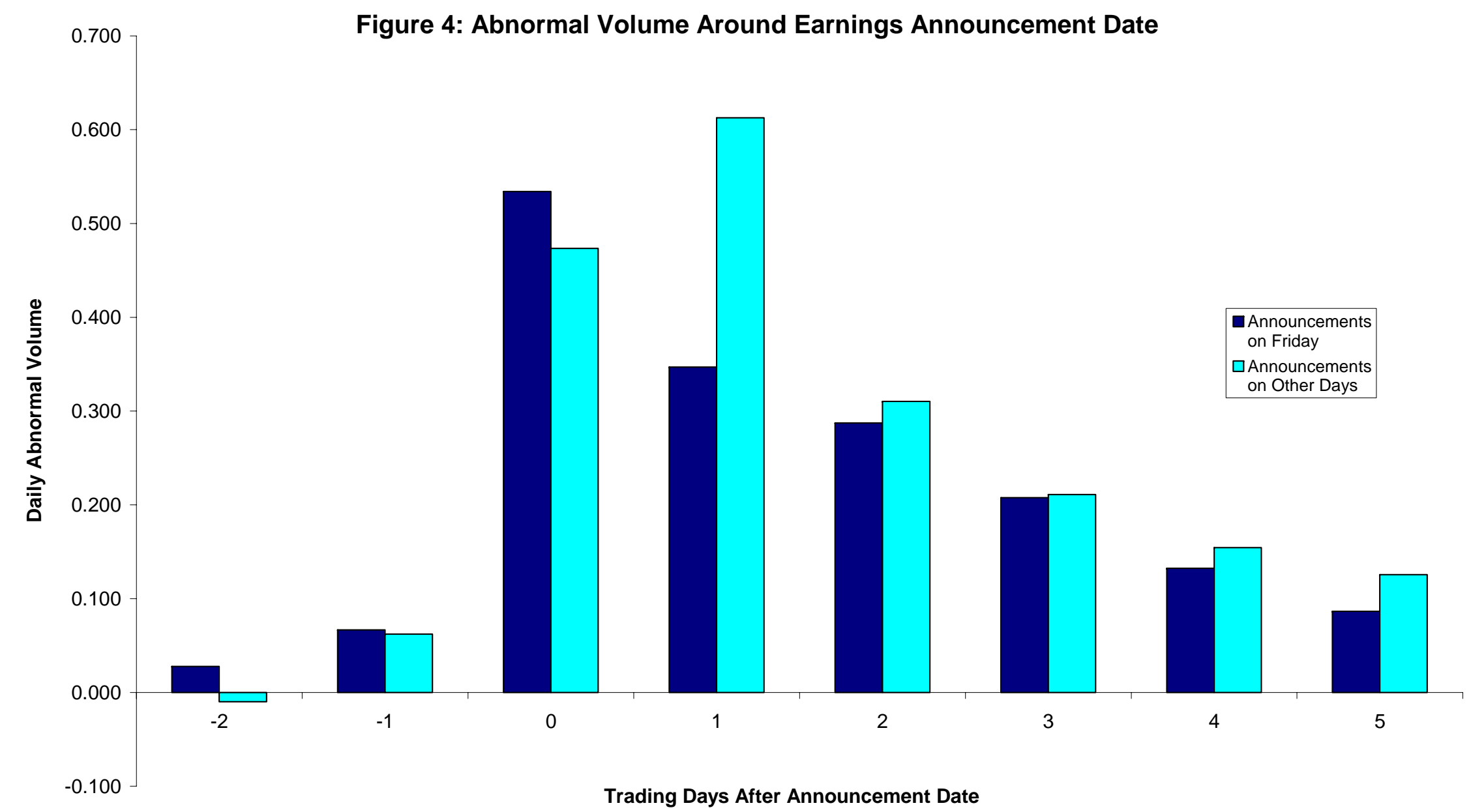

Figure 4. Stocks in CRSP are matched to quarterly earnings announcements in I/B/E/S from January 1995 until June 2006. In event time, day 0 is the day of the announcement. The abnormal volume for each stock is the average log volume on the day of and the day after the announcement, divided by the average log volume for the period - 20 to -11 in event time (10 trading days). Announcements made on Saturday or Sunday are excluded from the sample. 
Table I

\section{Summary Statistics}

Stocks in CRSP are matched to quarterly earnings announcements in I/B/E/S from January 1995 until June 2006. The earnings surprise for a quarterly announcement is the difference between actual earnings for the quarter recorded by $\mathrm{l} / \mathrm{B} / \mathrm{E} / \mathrm{S}$ and the median analyst forecast included in the I/B/E/S detail file during the 30 days before the quarterly earnings announcement scaled by the stock price 5 trading days before the announcement. Announcements made on Saturday or Sunday are excluded from the sample.

In Panel A we present the distribution of earnings announcements by weekday. In Columns 1-2 and 5-6 of Panel B we present summary statistics, with standard deviations in parentheses. In Column 3 of Panel B we present the difference between Columns 1 and 2, with standard errors for the difference. In Column 6 of Panel B we present the difference between Columns 4 and 5, with standard errors for the difference. The Homogeneous Sample refers to announcements by companies that announced earnings both on Friday and other weekdays at least ten percent of the time. In Panel $\mathrm{C}$ we present the average earnings surprise by quantile separately for announcements made on Friday and on other weekdays. Quantiles 1 through 5 contain earnings announcements for five quintiles of negative earnings surprises and quantiles 7 through 11 contain earnings surprises for five quintiles of positive earnings surprises. Quantile number 6 contains all announcements with an earnings surprise equal to zero. Since the number of negative earnings surprises, of positive earnings surprises, and of surprises equal to zero are unequal, the number of observations in each quantile differ. The breakpoints for the quantiles are determined separately for each year.

\begin{tabular}{lcccccc}
\hline \multicolumn{7}{c}{ Panel A: Distribution of Earnings Announcements by Day of the Week } \\
\hline \multirow{3}{*}{ Number } & All & Monday & Tuesday & Wednesday & Thursday & Friday \\
\cline { 2 - 7 } Fraction & 143583 & 19861 & 36358 & 36822 & 42376 & 8166 \\
& 1.0000 & 0.1383 & 0.2532 & 0.2565 & 0.2951 & 0.0569
\end{tabular}

Panel B: Differences Between Announcements on Friday and Other Weekdays

\begin{tabular}{|c|c|c|c|c|c|c|c|c|c|c|c|c|}
\hline & & \multicolumn{5}{|c|}{ Baseline Sample } & & \multicolumn{5}{|c|}{ Homogeneous Sample } \\
\hline & & \multicolumn{2}{|c|}{$\begin{array}{c}\text { Friday } \\
(1) \\
\end{array}$} & \multicolumn{2}{|c|}{$\begin{array}{c}\text { Non-Friday } \\
(2) \\
\end{array}$} & \multicolumn{2}{|c|}{$\begin{array}{c}\text { Difference } \\
(3) \\
\end{array}$} & $\begin{array}{c}\text { Friday } \\
(4) \\
\end{array}$ & \multicolumn{2}{|c|}{$\begin{array}{c}\text { Non-Friday } \\
(5) \\
\end{array}$} & \multicolumn{2}{|c|}{$\begin{array}{c}\text { Difference } \\
(6) \\
\end{array}$} \\
\hline \multicolumn{2}{|c|}{ Earnings surprise } & \multicolumn{2}{|c|}{$\begin{array}{c}-0.0039 \\
(0.0353)\end{array}$} & \multicolumn{2}{|c|}{$\begin{array}{c}-0.0009 \\
(0.0231)\end{array}$} & \multicolumn{2}{|c|}{$\begin{array}{c}-0.0030 \\
(0.0004)^{\star \star \star}\end{array}$} & $\begin{array}{l}-0.0043 \\
(0.0370)\end{array}$ & \multicolumn{2}{|c|}{$\begin{array}{l}-0.0016 \\
(0.0256)\end{array}$} & \multicolumn{2}{|c|}{$\begin{array}{c}-0.0027 \\
(0.0005)^{\star \star \star}\end{array}$} \\
\hline \multicolumn{2}{|c|}{ Market Cap (\$M) } & \multicolumn{2}{|c|}{$\begin{array}{c}3295 \\
(17599)\end{array}$} & \multicolumn{2}{|c|}{$\begin{array}{c}3564 \\
(15264)\end{array}$} & \multicolumn{2}{|l|}{$\begin{array}{l}-269 \\
(199)\end{array}$} & $\begin{array}{c}3270 \\
(18717)\end{array}$ & \multicolumn{2}{|c|}{$\begin{array}{c}2630 \\
(14755)\end{array}$} & \multicolumn{2}{|c|}{$\begin{array}{c}639 \\
(264)^{\star \star}\end{array}$} \\
\hline \multicolumn{2}{|l|}{ Year } & \multicolumn{2}{|c|}{$\begin{array}{c}1999.52 \\
(3.36)\end{array}$} & \multicolumn{2}{|c|}{$\begin{array}{c}2000.05 \\
(3.29)\end{array}$} & \multicolumn{2}{|c|}{$\begin{array}{c}-0.53 \\
(0.0382)^{\star \star \star}\end{array}$} & $\begin{array}{c}1999.49 \\
(3.34)\end{array}$ & \multicolumn{2}{|c|}{$\begin{array}{c}1999.65 \\
(3.29)\end{array}$} & \multicolumn{2}{|c|}{$\begin{array}{c}-0.16 \\
(.0489)^{\star \star \star}\end{array}$} \\
\hline \multicolumn{2}{|c|}{ Month 1 in Quarter } & \multicolumn{2}{|c|}{$\begin{array}{c}0.5797 \\
(0.4936)\end{array}$} & \multicolumn{2}{|c|}{$\begin{array}{c}0.6059 \\
(0.4886)\end{array}$} & \multicolumn{2}{|c|}{$\begin{array}{c}-0.0262 \\
(0.0056)^{\star \star \star}\end{array}$} & $\begin{array}{c}0.5906 \\
(0.4918)\end{array}$ & \multicolumn{2}{|c|}{$\begin{array}{c}0.5909 \\
(0.4917)\end{array}$} & \multicolumn{2}{|c|}{$\begin{array}{l}-0.0003 \\
(0.0072)\end{array}$} \\
\hline Month 2 in & Quarter & $\begin{array}{c}0.31 \\
(0.46\end{array}$ & $\begin{array}{l}166 \\
652)\end{array}$ & $\begin{array}{r}0.311 \\
(0.463\end{array}$ & & $\begin{array}{r}0.0052 \\
(0.0052\end{array}$ & & $\begin{array}{c}0.3146 \\
(0.4644)\end{array}$ & & $\begin{array}{l}.3174 \\
.4655)\end{array}$ & & $\begin{array}{l}0028 \\
0068)\end{array}$ \\
\hline Month 3 in & Quarter & $\begin{array}{r}0.10 \\
(0.30\end{array}$ & $\begin{array}{l}037 \\
049)\end{array}$ & $\begin{array}{r}0.082 \\
(0.275\end{array}$ & & $\begin{array}{r}0.0210 \\
(0.0034)^{*}\end{array}$ & & $\begin{array}{c}0.0948 \\
(0.2930)\end{array}$ & & $\begin{array}{l}.0917 \\
.2886)\end{array}$ & $\begin{array}{r}0.0 \\
(0.0\end{array}$ & $\begin{array}{l}0031 \\
0042)\end{array}$ \\
\hline $\mathrm{N}$ & & $N=\varepsilon$ & 8166 & $N=135$ & 5417 & $N=1435$ & & $N=5896$ & $N=$ & 21234 & $N=$ & 27130 \\
\hline${ }^{*}$ significan & t at $10 \%$ & ; ** signif & ficant at & 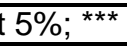 & signific & cant at $1 \%$ & & & & & & \\
\hline & & & Panel C: & Averag & e Surpri & rise by Ear & rning Surpri & prise Quar & tile & & & \\
\hline & Quantile & $\begin{array}{c}1 \\
\text { Low }\end{array}$ & 2 & 3 & 4 & 5 & $\begin{array}{c}6 \\
\text { Surprise }=0\end{array}$ & 0 & 8 & 9 & 10 & $\begin{array}{c}11 \\
\text { High }\end{array}$ \\
\hline Friday & $\begin{array}{l}\text { Average } \\
\mathrm{N}\end{array}$ & $\begin{array}{c}-0.0523 \\
833\end{array}$ & $\begin{array}{c}-0.0065 \\
763\end{array}$ & $\begin{array}{c}-0.0025 \\
627\end{array}$ & $\begin{array}{c}-0.0011 \\
585\end{array}$ & $\begin{array}{c}1-0.0004 \\
480\end{array}$ & $\begin{array}{c}0.0000 \\
995\end{array}$ & $\begin{array}{c}0.0003 \\
628\end{array}$ & $\begin{array}{c}0.0007 \\
686\end{array}$ & $\begin{array}{c}0.0014 \\
737\end{array}$ & $\begin{array}{c}0.0028 \\
846\end{array}$ & $\begin{array}{c}0.0152 \\
986\end{array}$ \\
\hline Other Days & $\begin{array}{l}\text { Average } \\
\mathrm{N}\end{array}$ & $\begin{array}{c}-0.0454 \\
7595\end{array}$ & $\begin{array}{c}-0.0064 \\
7582\end{array}$ & $\begin{array}{c}-0.0025 \\
7587\end{array}$ & $\begin{array}{c}-0.0011 \\
7589\end{array}$ & $\begin{array}{c}1-0.0004 \\
7576\end{array}$ & $\begin{array}{l}0.0000 \\
20109\end{array}$ & $\begin{array}{l}0.0003 \\
15484\end{array}$ & $\begin{array}{l}0.0007 \\
15473\end{array}$ & $\begin{array}{l}0.0014 \\
15475\end{array}$ & $\begin{array}{l}0.0028 \\
15475\end{array}$ & $\begin{array}{l}0.0143 \\
15472\end{array}$ \\
\hline
\end{tabular}


Table II

Stock Price Response to Earnings Announcements for the Top and Bottom Groups

Stocks in CRSP are matched to quarterly earnings announcements in I/B/E/S from January 1995 until June 2006 . In event time, day 0 is the day of the announcement. The cumulative abnormal return for each stock is the raw buy-and-hold return adjusted using the estimated beta from market model. The earnings surprise for an announcement is the difference between actual earnings for the quarter recorded by I/B/E/S and the median analyst forecast included in the I/B/E/S detail file during the 30 days before the quarterly earnings announcement scaled by the stock price 5 trading days before the announcement. Quantiles 1 through 5 contain earnings announcements for five quintiles of negative earnings surprises and quantiles 7 through 11 contain earnings surprises for five quintiles of positive earnings surprises. Quantile number 6 contains all announcements with an earnings surprise equal to zero. Since the number of negative earnings surprises, of positive earnings surprises, and of surprises equal to zero are unequal, the number of observations in each quantile differ. In some specifications we follow a similar procedure but sort announcements into surprise deciles instead of quantiles.

The breakpoints for the quantiles (deciles) are determined separately for each year. The coefficients in the Table are evaluated at the average value of the controls. Columns 1, 2, 3 only include observations from the top quantile (11) and the bottom quantile (1). Column 4 includes only observations from the top decile (10) and bottom decile (1). Columns 5 and 6 only include observations from the top two quantiles (10 and 11$)$ or the bottom two quantiles (1 and 2). Column 7 includes only observations from the top two deciles (9 and 10) and bottom two deciles (1 and 2).

The standard set of controls includes indicators for the year of announcement, the month of announcement, and the decile of a firm's market capitalization. The additional earnings surprise volatility controls in Columns $3,4,6$, and 7 are indicators for the decile of the company's earnings surprise standard deviation during the previous 4 years (requiring at least 4 observations). Whenever a group of controls is included in these regressions, each control is also interacted with the indicator variable for the top quantile (or top two quantiles). Announcements made on Saturday or Sunday are excluded from the sample. Standard errors adjusted for heteroskedasticity and clustered by day of announcement are in parentheses.

\begin{tabular}{|c|c|c|c|c|c|c|c|}
\hline \multicolumn{8}{|c|}{ Panel A: The Dependent Variable is the Cumulative Abnormal Return in Event Time From 0 to 1} \\
\hline & (1) & (2) & (3) & (4) & (5) & (6) & (7) \\
\hline Constant & $\begin{array}{c}-0.0369 \\
(0.0013)^{\star \star \star}\end{array}$ & $\begin{array}{c}-0.0370 \\
(0.0024)^{\star \star \star}\end{array}$ & $\begin{array}{c}-0.0340 \\
(0.0019)^{\star \star \star}\end{array}$ & $\begin{array}{c}-0.0330 \\
(0.0011)^{\star \star \star}\end{array}$ & $\begin{array}{c}-0.0334 \\
(0.0009)^{\star \star \star}\end{array}$ & $\begin{array}{c}-0.0322 \\
(0.0012)^{\star \star \star}\end{array}$ & $\begin{array}{c}-0.0254 \\
(0.0007)^{\star \star \star}\end{array}$ \\
\hline Friday & $\begin{array}{c}0.0021 \\
(0.0040)\end{array}$ & $\begin{array}{c}0.0003 \\
(0.0040)\end{array}$ & $\begin{array}{c}0.0015 \\
(0.0043)\end{array}$ & $\begin{array}{c}0.0010 \\
(0.0031)\end{array}$ & $\begin{array}{c}0.0024 \\
(0.0027)\end{array}$ & $\begin{array}{c}0.0012 \\
(0.0029)\end{array}$ & $\begin{array}{c}0.0008 \\
(0.0022)\end{array}$ \\
\hline Top Group & $\begin{array}{c}0.0659 \\
(0.0014)^{\star \star \star}\end{array}$ & $\begin{array}{c}0.0634 \\
(0.0015)^{\star \star \star}\end{array}$ & $\begin{array}{c}0.0640 \\
(0.0021)^{\star \star \star}\end{array}$ & $\begin{array}{c}0.0635 \\
(0.0014)^{\star \star \star}\end{array}$ & & & \\
\hline (Top Group)^Friday & $\begin{array}{c}-0.0081 \\
(0.0047)^{\star}\end{array}$ & $\begin{array}{l}-0.0059 \\
(0.0048)\end{array}$ & $\begin{array}{c}-0.0090 \\
(0.0050)^{\star}\end{array}$ & $\begin{array}{l}-0.0071 \\
(0.0044)\end{array}$ & & & \\
\hline Top Two Groups & & & & & $\begin{array}{c}0.0582 \\
(0.0010)^{\star \star \star}\end{array}$ & $\begin{array}{c}0.0571 \\
(0.0013)^{\star \star \star}\end{array}$ & $\begin{array}{c}0.0518 \\
(0.0009)^{\star \star \star}\end{array}$ \\
\hline (Top Two Groups)^Friday & & & & & $\begin{array}{c}-0.0092 \\
(0.0031)^{\star \star \star}\end{array}$ & $\begin{array}{c}-0.0086 \\
(0.0034)^{\star \star \star}\end{array}$ & $\begin{array}{c}-0.0095 \\
(0.0028)^{\star \star \star}\end{array}$ \\
\hline Standard Controls (Interacted) & & $\mathrm{X}$ & $\mathrm{X}$ & $\mathrm{X}$ & & $x$ & $X$ \\
\hline Surprise Volatility Controls (Interacted) & & & $x$ & $\mathrm{X}$ & & $x$ & $x$ \\
\hline Sorting Procedure & 11 Quantiles & 11 Quantiles & 11 Quantiles & 10 Deciles & 11 Quantiles & 11 Quantiles & 10 Deciles \\
\hline $\mathrm{R}^{2}$ & 0.0915 & 0.0990 & 0.1049 & 0.1148 & 0.0864 & 0.0985 & 0.0986 \\
\hline$N$ & $N=24874$ & $N=24874$ & $N=19888$ & $N=23458$ & $N=49538$ & $N=40331$ & $N=47879$ \\
\hline \multicolumn{8}{|c|}{ Panel B: The Dependent Variable is the Cumulative Abnormal Return in Event Time From 2 to 75} \\
\hline & (1) & (2) & (3) & (4) & (5) & (6) & $(7)$ \\
\hline Constant & $\begin{array}{c}-0.0165 \\
(0.0057)^{\star \star \star}\end{array}$ & $\begin{array}{c}-0.0180 \\
(0.0059)^{\star \star \star}\end{array}$ & $\begin{array}{l}-0.0014 \\
(0.0063)\end{array}$ & $\begin{array}{c}-0.0048 \\
(0.0044)^{\star \star \star}\end{array}$ & $\begin{array}{c}-0.0116 \\
(0.0041)^{\star \star \star}\end{array}$ & $\begin{array}{c}-0.0029 \\
(0.0041)^{\star \star \star}\end{array}$ & $\begin{array}{c}-0.0014 \\
(0.0030)^{\star \star \star}\end{array}$ \\
\hline Friday & $\begin{array}{c}-0.0382 \\
(0.0148)^{\star \star \star}\end{array}$ & $\begin{array}{c}-0.0272 \\
(0.0138)^{\star \star}\end{array}$ & $\begin{array}{c}-0.0432 \\
(0.0147)^{\star \star \star}\end{array}$ & $\begin{array}{c}-0.0258 \\
(0.0107)^{\star \star}\end{array}$ & $\begin{array}{c}-0.0220 \\
(0.0102)^{\star \star}\end{array}$ & $\begin{array}{c}-0.0265 \\
(0.0099)^{\star \star \star}\end{array}$ & $\begin{array}{c}-0.0140 \\
(0.0071)^{\star \star}\end{array}$ \\
\hline Top Group & $\begin{array}{c}0.0514 \\
(0.0055)^{\star \star \star}\end{array}$ & $\begin{array}{c}0.0552 \\
(0.0059)^{\star \star \star}\end{array}$ & $\begin{array}{c}0.0484 \\
(0.0070)^{\star \star \star}\end{array}$ & $\begin{array}{c}0.0510 \\
(0.0056)^{\star \star \star}\end{array}$ & & & \\
\hline (Top Group)*Friday & $\begin{array}{c}0.0462 \\
(0.0175)^{\star \star \star}\end{array}$ & $\begin{array}{c}0.0392 \\
(0.0171)^{\star \star}\end{array}$ & $\begin{array}{c}0.0462 \\
(0.0184)^{\star \star}\end{array}$ & $\begin{array}{c}0.0208 \\
(0.0157)\end{array}$ & & & \\
\hline Top Two Groups & & & & & $\begin{array}{c}0.0434 \\
(0.0036)^{\star \star \star}\end{array}$ & $\begin{array}{c}0.0453 \\
(0.0044)^{\star \star \star}\end{array}$ & $\begin{array}{c}0.0449 \\
(0.0036)^{\star \star \star}\end{array}$ \\
\hline (Top Two Groups)^Friday & & & & & $\begin{array}{c}0.0305 \\
(0.0118)^{\star \star \star}\end{array}$ & $\begin{array}{c}0.0350 \\
(0.0125)^{\star \star \star}\end{array}$ & $\begin{array}{c}0.0216 \\
(0.0114)^{\star}\end{array}$ \\
\hline Standard Controls (Interacted) & & $X$ & $x$ & $x$ & & $\mathrm{X}$ & $\mathrm{X}$ \\
\hline Surprise Volatility Controls (Interacted) & & & $X$ & $X$ & & $X$ & $X$ \\
\hline Sorting Procedure & 11 Quantiles & 11 Quantiles & 11 Quantiles & 10 Deciles & 11 Quantiles & 11 Quantiles & 10 Deciles \\
\hline $\mathrm{R}^{2}$ & 0.0056 & 0.0405 & 0.0426 & 0.0401 & 0.0045 & 0.0350 & 0.0324 \\
\hline $\mathrm{N}$ & $N=24874$ & $N=24874$ & $N=19888$ & $N=23458$ & $N=49538$ & $N=40331$ & $N=47879$ \\
\hline
\end{tabular}

\footnotetext{
* significant at $10 \%$; ** significant at $5 \%$; ** significant at $1 \%$
} 


\section{Table II (Cont.)}

\section{Stock Price Response for the Top and Bottom Groups and Delayed Response Ratio}

Stocks in CRSP are matched to quarterly earnings announcements in I/B/E/S from January 1995 until June 2006 . In event time, day 0 is the day of the announcement. The cumulative abnormal return for each stock is the raw buy-and-hold return adjusted using the estimated beta from market model. The earnings surprise for an announcement is the difference between actual earnings for the quarter recorded by I/B/E/S and the median analyst forecast included in the I/B/E/S detail file during the 30 days before the quarterly earnings announcement scaled by the stock price 5 trading days before the announcement. Quantiles 1 through 5 contain earnings announcements for five quintiles of negative earnings surprises and quantiles 7 through 11 contain earnings surprises for five quintiles of positive earnings surprises. Quantile number 6 contains all announcements with an earnings surprise equal to zero. Since the number of negative earnings surprises, of positive earnings surprises, and of surprises equal to zero are unequal, the number of observations in each quantile differ. In some specifications we follow a similar procedure but sort announcements into surprise deciles instead of quantiles.

The breakpoints for the quantiles (deciles) are determined separately for each year. The coefficients in the Table are evaluated at the average value of the controls. Columns 1, 2, 3 only include observations from the top quantile (11) and the bottom quantile (1). Column 4 includes only observations from the top decile (10) and bottom decile (1). Columns 5 and 6 only include observations from the top two quantiles (10 and 11$)$ or the bottom two quantiles (1 and 2). Column 7 includes only observations from the top two deciles (9 and 10) and bottom two deciles (1 and 2).

The standard set of controls includes indicators for the year of announcement, the month of announcement, and the decile of a firm's market capitalization. The additional earnings surprise volatility controls in Columns 3, 4, 6, and 7 are indicators for the decile of the company's earnings surprise standard deviation during the previous 4 years (requiring at least 4 observations). Whenever a group of controls is included in these regressions, each control is also interacted with the indicator variable for the top quantile (or top two quantiles). Announcements made on Saturday or Sunday are excluded from the sample. Standard errors adjusted for heteroskedasticity and clustered by day of announcement are in parentheses.

\begin{tabular}{|c|c|c|c|c|c|c|c|}
\hline \multicolumn{8}{|c|}{ Panel C: The Dependent Variable is the Cumulative Abnormal Return in Event Time From 0 to 75} \\
\hline & (1) & (2) & (3) & (4) & (5) & (6) & $(7)$ \\
\hline Constant & $\begin{array}{c}-0.0527 \\
(0.0057)^{\star \star \star}\end{array}$ & $\begin{array}{c}-0.0528 \\
(0.0059)^{\star \star \star}\end{array}$ & $\begin{array}{c}-0.0372 \\
(0.0063)^{\star \star \star}\end{array}$ & $\begin{array}{c}-0.0382 \\
(0.0045)^{\star \star \star}\end{array}$ & $\begin{array}{c}-0.0447 \\
(0.0041)^{\star \star \star}\end{array}$ & $\begin{array}{c}-0.0359 \\
(0.0042)^{\star \star \star}\end{array}$ & $\begin{array}{c}-0.0273 \\
(0.0031)^{\star \star \star}\end{array}$ \\
\hline Friday & $\begin{array}{c}-0.0370 \\
(0.0148)^{\star \star}\end{array}$ & $\begin{array}{c}-0.0278 \\
(0.0138)^{\star \star}\end{array}$ & $\begin{array}{c}-0.0445 \\
(0.0141)^{\star \star \star}\end{array}$ & $\begin{array}{c}-0.0268 \\
(0.0107)^{\star \star}\end{array}$ & $\begin{array}{c}-0.0204 \\
(0.0104)^{\star}\end{array}$ & $\begin{array}{c}-0.0271 \\
(0.0098)^{\star \star \star}\end{array}$ & $\begin{array}{c}-0.0138 \\
(0.0074)^{\star}\end{array}$ \\
\hline Top Group & $\begin{array}{c}0.1210 \\
(0.0057)^{\star \star \star}\end{array}$ & $\begin{array}{c}0.1218 \\
(0.0056)^{\star \star \star}\end{array}$ & $\begin{array}{c}0.1178 \\
(0.0075)^{\star \star \star}\end{array}$ & $\begin{array}{c}0.1189 \\
(0.0060)^{\star \star \star}\end{array}$ & & & \\
\hline (Top Group)`Friday & $\begin{array}{c}0.0368 \\
(0.0182)^{\star \star}\end{array}$ & $\begin{array}{c}0.0323 \\
(0.0179)^{\star}\end{array}$ & $\begin{array}{c}0.0382 \\
(0.0184)^{\star \star}\end{array}$ & $\begin{array}{c}0.0136 \\
(0.0161)\end{array}$ & & & \\
\hline Top Two Groups & & & & & $\begin{array}{c}0.1046 \\
(0.0037)^{\star \star \star}\end{array}$ & $\begin{array}{c}0.1063 \\
(0.0047)^{\star \star \star}\end{array}$ & $\begin{array}{c}0.1008 \\
(0.0039)^{\star \star \star}\end{array}$ \\
\hline (Top Two Groups)`Friday & & & & & $\begin{array}{c}0.0213 \\
(0.0124)^{\star}\end{array}$ & $\begin{array}{c}0.0276 \\
(0.0127)^{\star \star}\end{array}$ & $\begin{array}{c}0.0119 \\
(0.0119)\end{array}$ \\
\hline Standard Controls (Interacted) & & $X$ & $X$ & $X$ & & $\mathrm{X}$ & $x$ \\
\hline Surprise Volatility Controls (Interacted) & & & $x$ & $x$ & & $x$ & $x$ \\
\hline Sorting Procedure & 11 Quantiles & 11 Quantiles & 11 Quantiles & 10 Deciles & 11 Quantiles & 11 Quantiles & 10 Deciles \\
\hline $\mathrm{R}^{2}$ & 0.0231 & 0.0564 & 0.0598 & 0.0587 & 0.0206 & 0.0503 & 0.0487 \\
\hline $\mathrm{N}$ & $N=24874$ & $N=24874$ & $N=19888$ & $N=23458$ & $N=49538$ & $N=40331$ & $N=47879$ \\
\hline \multicolumn{8}{|c|}{ Panel D: Ratio of the Delayed Stock Response (2 to 75) to the Long-term Stock Response (0 to 75) } \\
\hline & $(1)$ & (2) & (3) & $(4)$ & (5) & (6) & $(7)$ \\
\hline $\begin{array}{l}\text { Response ratio for Friday } \\
\text { announcements }\end{array}$ & $\begin{array}{c}0.6187 \\
(0.0443)\end{array}$ & $\begin{array}{c}0.6083 \\
(0.0459)\end{array}$ & $\begin{array}{c}0.6020 \\
(0.0536)\end{array}$ & $\begin{array}{c}0.5388 \\
(0.0578)\end{array}$ & $\begin{array}{c}0.5869 \\
(0.0401)\end{array}$ & $\begin{array}{c}0.5973 \\
(0.0420)\end{array}$ & $\begin{array}{c}0.5883 \\
(0.0428)\end{array}$ \\
\hline $\begin{array}{l}\text { Response ratio for announcements on } \\
\text { other days }\end{array}$ & $\begin{array}{c}0.4244 \\
(0.0270)\end{array}$ & $\begin{array}{c}0.4491 \\
(0.0273)\end{array}$ & $\begin{array}{c}0.4068 \\
(0.0361)\end{array}$ & $\begin{array}{c}0.4257 \\
(0.0270)\end{array}$ & $\begin{array}{c}0.4144 \\
(0.0207)\end{array}$ & $\begin{array}{c}0.4241 \\
(0.0245)\end{array}$ & $\begin{array}{c}0.4444 \\
(0.0200)\end{array}$ \\
\hline $\begin{array}{l}\text { Difference between the response ratio } \\
\text { for Friday and other days }\end{array}$ & $\begin{array}{c}0.1942 \\
(0.0519)^{\star \star \star}\end{array}$ & $\begin{array}{c}0.1591 \\
(0.0517)^{\star \star \star}\end{array}$ & $\begin{array}{c}0.1952 \\
(0.0612)^{\star \star \star}\end{array}$ & $\begin{array}{c}0.1131 \\
(0.0619)^{\star}\end{array}$ & $\begin{array}{c}0.1725 \\
(0.0451)^{\star \star \star}\end{array}$ & $\begin{array}{c}0.1732 \\
(0.0464)^{\star \star \star}\end{array}$ & $\begin{array}{c}0.1439 \\
(0.0460)^{\star \star \star}\end{array}$ \\
\hline Standard Controls (Interacted) & & $x$ & $x$ & $x$ & & $\mathrm{X}$ & $x$ \\
\hline Surprise Volatility Controls (Interacted) & & & $\mathrm{x}$ & $\mathrm{X}$ & & $\mathrm{x}$ & $\mathrm{x}$ \\
\hline Sorting Procedure & 11 Quantiles & 11 Quantiles & 11 Quantiles & 10 Deciles & 11 Quantiles & 11 Quantiles & 10 Deciles \\
\hline $\mathrm{N}$ & $N=24874$ & $N=24874$ & $N=19888$ & $N=23458$ & $N=49538$ & $N=40331$ & $N=47879$ \\
\hline
\end{tabular}


Table III

Stock Price Response to Earnings Announcements For All Announcements

Stocks in CRSP are matched to quarterly earnings announcements in I/B/E/S from January 1995 until June 2006 . In event time, day 0 is the day of the announcement. The cumulative abnormal return for each stock is the raw buy-and-hold return adjusted using the estimated beta from market model. The earnings surprise for an announcement is the difference between actual earnings for the quarter recorded by $\mathrm{I} / \mathrm{B} / \mathrm{E} / \mathrm{S}$ and the median analyst forecast included in the I/B/E/S detail file during the 30 days before the quarterly earnings announcement scaled by the stock price 5 trading days before the announcement. Quantiles 1 through 5 contain earnings announcements for five quintiles of negative earnings surprises and quantiles 7 through 11 contain earnings surprises for five quintiles of positive earnings surprises. Quantile number 6 contains all announcements with an earnings surprise equal to zero. Since the number of negative earnings surprises, of positive earnings surprises, and of surprises equal to zero are unequal, the number of observations in each quantile differ. In Columns 3 and 6 we follow a similar procedure but sort announcements into surprise deciles instead of quantiles.

The breakpoints for the quantiles (deciles) are determined separately for each year. The standard set of controls includes indicators for the year of announcement, the month of announcement, and the decile of a firm's market capitalization. The controls are present in levels and interacted with the quantile (decile) variable. Announcements made on Saturday or Sunday are excluded from the sample. Estimates from OLS regressions are reported in each column. Standard errors adjusted for heteroskedasticity and clustered by day of announcement are in parentheses.

\begin{tabular}{|c|c|c|c|c|c|c|}
\hline & \multicolumn{3}{|c|}{$\begin{array}{c}\text { Dependent Variable: Cumulative Abnormal Return in } \\
\text { Event Time from } 0 \text { to } 1\end{array}$} & \multicolumn{3}{|c|}{$\begin{array}{c}\text { Dependent Variable: Cumulative Abnormal Return in } \\
\text { Event Time from } 2 \text { to } 75\end{array}$} \\
\hline & $(1)$ & $(2)$ & $(3)$ & $(4)$ & $(5)$ & $(6)$ \\
\hline Friday & $\begin{array}{c}0.0067 \\
(0.0023)^{\star \star \star}\end{array}$ & $\begin{array}{c}0.0044 \\
(0.0023)^{\star}\end{array}$ & $\begin{array}{c}0.0025 \\
(0.0019)\end{array}$ & $\begin{array}{c}-0.0155 \\
(0.0086)^{\star}\end{array}$ & $\begin{array}{l}-0.0122 \\
(0.0080)\end{array}$ & $\begin{array}{l}-0.0098 \\
(0.0069)\end{array}$ \\
\hline Earnings Surprise Quantile & $\begin{array}{c}0.0065 \\
(0.0001)^{\star \star \star}\end{array}$ & $\begin{array}{c}0.0047 \\
(0.0004)^{\star \star \star}\end{array}$ & & $\begin{array}{c}0.0048 \\
(0.0003)^{\star \star \star}\end{array}$ & $\begin{array}{c}0.0069 \\
(0.0015)^{\star \star \star}\end{array}$ & \\
\hline (Earnings Surprise Quantile)^Friday & $\begin{array}{c}-0.0011 \\
(0.0003)^{\star \star \star}\end{array}$ & $\begin{array}{c}-0.0008 \\
(0.0003)^{\star \star \star}\end{array}$ & & $\begin{array}{c}0.0027 \\
(0.0011)^{\star \star}\end{array}$ & $\begin{array}{c}0.0023 \\
(0.0011)^{\star \star}\end{array}$ & \\
\hline Earnings Surprise Decile & & & $\begin{array}{c}0.0051 \\
(0.0004)^{\star \star \star}\end{array}$ & & & $\begin{array}{c}0.0087 \\
(0.0015)^{\star \star \star}\end{array}$ \\
\hline (Earnings Surprise Decile)^Friday & & & $\begin{array}{c}-0.0008 \\
(0.0003)^{\star \star \star}\end{array}$ & & & $\begin{array}{c}0.0024 \\
(0.0011)^{\star \star}\end{array}$ \\
\hline Standard Controls (interacted) & & $\mathrm{x}$ & $\mathrm{X}$ & & $x$ & $\mathrm{x}$ \\
\hline $\mathrm{R}^{2}$ & 0.0582 & 0.0619 & 0.0600 & 0.0028 & 0.0206 & 0.0205 \\
\hline $\mathrm{N}$ & $N=143,580$ & $N=143,580$ & $N=143,580$ & $N=143,580$ & $N=143,580$ & $N=143,580$ \\
\hline
\end{tabular}




\section{Table IV}

\section{Performance of Post-Earnings Announcement Drift Portfolios}

Stocks in CRSP are matched to quarterly earnings announcements in I/B/E/S from January 1995 until June 2006. The earnings surprise for an announcement is the difference between actual earnings for the quarter recorded by I/B/E/S and the median analyst forecast included in the I/B/E/S detail file during the 30 days before the quarterly earnings announcement scaled by the stock price 5 trading days before the announcement. Quantiles 1 through 5 contain earnings announcements for five quintiles of negative earnings surprises and quantiles 7 through 11 contain earnings surprises for five quintiles of positive earnings surprises. Quantile number 6 contains all announcements with an earnings surprise equal to zero. Announcements made on Saturday or Sunday are excluded from the sample. The sorting mechanism in the portfolio strategies analyzed below uses the breakpoints for the quantiles determined by non-Friday announcements during the previous calendar year.

At the end of calendar month t-1 the zero-investment drift portfolio for month t using Friday announcements (other weekdays) is created as follows. The strategy purchases stocks with earnings surprise announcements in the highest (or highest two) quantile(s) and sells stocks with earnings surprises in the lowest (or lowest two) quantile(s) in month t-1. The return for the differential drift portfolio is the difference between the return of the drift portfolio for Friday announcements and the return of the drift portfolio for non-Friday announcements. For a stock to be included in the one-month holding period strategy for month $t$ the second trading day after the announcement must be in month $\mathrm{t}-1$. For a stock to be included in the two-month holding period drift strategy for month $\mathrm{t}$, the second trading day after the announcement must be in month $\mathrm{t}-1$ or in month $\mathrm{t}-2$. If there are no stocks in a constituent portfolio, then that month is excluded from the analysis. Returns are equally-weighted within the constituent portfolios. Columns 1 through 6 report the coefficients of OLS regressions of the differential drift portfolio monthly returns from January 1995 to June 2006 on monthly factors. VWRF is the return on the CRSP valueweighted stock index minus the 1-month treasury rate. SMB, HML, and UMD are the returns on the factor-mimicking portfolios for size, book-to-market and momentum, respectively. The constant is the average monthly risk-adjusted return. Heteroskedasticity and autocorrelation consistent standard errors are calculated using the Newey-West estimator with 6 lags (in parentheses). Columns 1 and 2 report results for the baseline specification. Column 3 reports results where the non-Friday drift portfolio only uses the non-Friday announcements that match the earnings surprises in the Friday drift portfolio (see details below). Column 4 reports results using the top two and bottom two quantiles. Column 5 reports results using a two month holding period. Column 6 reports results for a decile sorting procedure that is analogous to the baseline methodology where the breakpoints for the top and bottom groups are determined by sorting earnings surprises into deciles during the previous calendar year.

The portfolio strategy in column 3 (matched sample) is designed to address the concern that the stocks in the constituent Friday portfolios have more extreme earnings surprises than the stocks in the constituent non-Friday portfolios. For every stock with a Friday earnings announcement in the bottom (top) quantile for month t-1 we find the five non-Friday announcements in the same quantile and month with the closest earnings surprise to the Friday announcement subject to the constraint that non-Friday surprises must be larger in absolute value (more extreme). If there are fewer than five non-Friday announcements with more extreme earnings surprises than a specific Friday announcement, the returns of the stocks with these non-Friday announcements are overweighted appropriately. Friday announcements that can not be matched to at least one non-Friday announcement with a more extreme earnings surprise are excluded from the analysis. Only announcements in this matched sample are used for the analysis in column 3 .

\begin{tabular}{|c|c|c|c|c|c|c|}
\hline \multirow[b]{3}{*}{ Constant } & \multicolumn{6}{|c|}{ Dependent Variable: Monthly Return on the Zero-Investment Portfolio } \\
\hline & $(1)$ & $(2)$ & $(3)$ & $(4)$ & $(5)$ & $(6)$ \\
\hline & $\begin{array}{c}0.0384 \\
(0.0134)^{\star \star \star}\end{array}$ & $\begin{array}{c}0.0462 \\
(0.0139)^{\star \star \star}\end{array}$ & $\begin{array}{c}0.0584 \\
(0.0220)^{\star \star \star}\end{array}$ & $\begin{array}{c}0.0218 \\
(0.0079)^{\star \star \star}\end{array}$ & $\begin{array}{c}0.0232 \\
(0.0086)^{\star \star \star}\end{array}$ & $\begin{array}{c}0.0277 \\
(0.0091)^{\star \star \star}\end{array}$ \\
\hline $\begin{array}{l}\text { VW Index Excess Return } \\
\text { (VWRF) }\end{array}$ & $\begin{array}{l}-0.2742 \\
(0.3090)\end{array}$ & $\begin{array}{l}-0.6419 \\
(0.2778)^{\star \star}\end{array}$ & $\begin{array}{l}-0.0968 \\
(0.4262)\end{array}$ & $\begin{array}{l}-0.1842 \\
(0.1865)\end{array}$ & $\begin{array}{l}-0.1068 \\
(0.2301)\end{array}$ & $\begin{array}{l}-0.4580 \\
(0.1937)^{\star \star}\end{array}$ \\
\hline $\begin{array}{l}\text { Size Factor Return } \\
\text { (SMB) }\end{array}$ & & $\begin{array}{c}0.2344 \\
(0.4195)\end{array}$ & $\begin{array}{c}0.5644 \\
(0.6227)\end{array}$ & $\begin{array}{l}-0.0390 \\
(0.2464)\end{array}$ & $\begin{array}{c}0.0701 \\
(0.2930)\end{array}$ & $\begin{array}{l}-0.0137 \\
(0.2438)\end{array}$ \\
\hline $\begin{array}{l}\text { Value Factor Return } \\
\text { (HML) }\end{array}$ & & $\begin{array}{l}-0.4607 \\
(0.6143)\end{array}$ & $\begin{array}{l}-1.5556 \\
(0.7277)^{\star \star}\end{array}$ & $\begin{array}{c}0.0762 \\
(0.3329)\end{array}$ & $\begin{array}{l}-0.3264 \\
(0.2840)\end{array}$ & $\begin{array}{l}-0.2094 \\
(0.3820)\end{array}$ \\
\hline $\begin{array}{l}\text { Momentum Factor Return } \\
\text { (UMD) }\end{array}$ & & $\begin{array}{l}-0.3994 \\
(0.2632)\end{array}$ & $\begin{array}{l}-1.1817 \\
(0.6559)^{\star}\end{array}$ & $\begin{array}{l}-0.0696 \\
(0.1740)\end{array}$ & $\begin{array}{l}-0.0410 \\
(0.2206)\end{array}$ & $\begin{array}{l}-0.3454 \\
(0.1940)^{\star}\end{array}$ \\
\hline One month holding period & $x$ & $\mathrm{x}$ & $x$ & $x$ & & $x$ \\
\hline Two month holding period & & & & & $x$ & \\
\hline Top minus bottom quantile & $x$ & $x$ & $\mathrm{x}$ & & $x$ & \\
\hline Matched sample & & & $x$ & & & \\
\hline Top two minus bottom two quantiles & & & & $\mathrm{X}$ & & \\
\hline Top minus bottom decile & & & & & & $\mathrm{x}$ \\
\hline $\mathrm{R}^{2}$ & 0.0073 & 0.0385 & 0.1736 & 0.0152 & 0.0153 & 0.0398 \\
\hline $\mathrm{N}$ & $N=125$ & $N=125$ & $N=124$ & $N=130$ & $N=138$ & $N=127$ \\
\hline
\end{tabular}




\section{Table V}

\section{Short-term Volume Response to an Earnings Announcement}

Stocks in CRSP are matched to quarterly earnings announcements in I/B/E/S from January 1995 until June 2006. In event time, day 0 is the day of the announcement. The abnormal volume for each stock is the average log volume on the day of and the day after the announcement, divided by the average log volume for the period -20 to -11 in event time (10 trading days). The aggregate abnormal volume is computed in a similar manner using volume for the whole market. The earnings surprise for an announcement is the difference between actual earnings for the quarter recorded by l/B/E/S and the median analyst forecast included in the l/B/E/S detail file during the 30 days before the quarterly earnings announcement scaled by the stock price 5 trading days before the announcement. Quantiles 1 through 5 contain earnings announcements for five quintiles of negative earnings surprises and quantiles 7 through 11 contain earnings surprises for 5 quintiles of positive earnings surprises. Quantile number 6 contains all announcements with an earnings surprise equal to zero. Since the number of negative earnings surprises, the number of surprises equal to zero, and the number of positive earnings surprises are not equal, the number of observations in each quantile differ. In Column 5 we follow a similar procedure but sort announcements into surprise deciles instead of quantiles. The breakpoints for the quantiles (deciles) are determined separately for each year. Indicators for each earnings surprise quantile (decile) are included in all regressions.

The standard set of controls includes indicators for the year of announcement, the month of announcement, and the decile of a firm's market capitalization. The additional earnings surprise volatility controls in Columns 4 and 5 are indicators for the decile of the company's earnings surprise standard deviation during the previous 4 years (requiring at least 4 observations). Announcements made on Saturday or Sunday are excluded from the sample. Estimates from OLS regressions are reported in each column. Standard errors adjusted for heteroskedasticity and clustered by day of announcement are in parentheses.

\begin{tabular}{|c|c|c|c|c|c|c|}
\hline & \multicolumn{5}{|c|}{ Dependent Variable: Abnormal Volume in Event Time from 0 to 1} & \multirow[b]{2}{*}{ (6) } \\
\hline & $(1)$ & $(2)$ & $(3)$ & $(4)$ & $(5)$ & \\
\hline Friday & $\begin{array}{c}-0.1109 \\
(0.0161)^{\star \star \star}\end{array}$ & $\begin{array}{c}-0.1235 \\
(0.0130)^{\star \star \star}\end{array}$ & $\begin{array}{c}-0.0436 \\
(0.0129)^{\star \star \star}\end{array}$ & $\begin{array}{c}-0.0413 \\
(0.0130)^{\star \star \star}\end{array}$ & $\begin{array}{c}-0.0414 \\
(0.0129)^{\star \star \star}\end{array}$ & $\begin{array}{l}-0.0173 \\
(0.0121)\end{array}$ \\
\hline Aggregate Abnormal Volume & & & & & & $\begin{array}{c}0.3977 \\
(0.0289)^{\star \star \star}\end{array}$ \\
\hline Earnings Surprise Quantiles & $\mathrm{X}$ & $\mathrm{X}$ & $\mathrm{X}$ & $\mathrm{X}$ & & $\mathrm{x}$ \\
\hline Earnings Surprise Deciles & & & & & $x$ & \\
\hline Standard Controls & & $\mathrm{X}$ & $x$ & $x$ & $x$ & $x$ \\
\hline Surprise Volatility Controls & & & & $x$ & $x$ & \\
\hline Company Fixed Effects & & & $x$ & $\mathrm{x}$ & $\mathrm{x}$ & $x$ \\
\hline $\mathrm{R}^{2}$ & 0.0072 & 0.0344 & 0.1963 & 0.1987 & 0.1984 & 0.2021 \\
\hline$N$ & $N=143369$ & $N=143369$ & $N=143369$ & $N=122325$ & $N=122325$ & $N=143369$ \\
\hline
\end{tabular}

* significant at 10\%; ** significant at 5\%; *** significant at $1 \%$ 
Table Al

Accuracy of the Imputed Date for Earnings Announcements

Newswire searches using Lexis-Nexis provide the actual date for the earnings announcement. The imputed date for the earnings announcement is generated from the recorded announcement dates in Compustat and I/B/E/S using a simple algorithm. The algorithm is described in the text and is designed to maximize the match between imputed and actual dates in the sample of 2487 observations randomly selected for a newswire search.

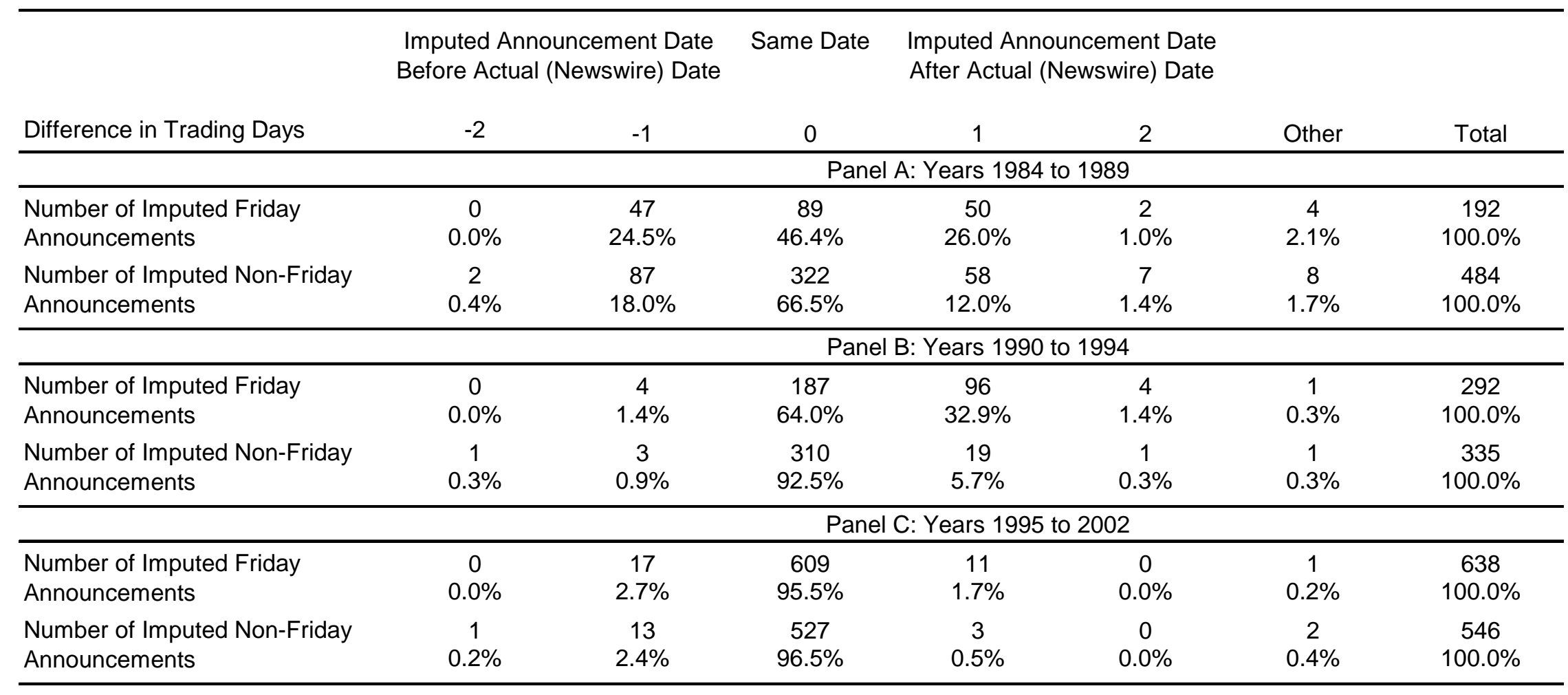

